\title{
Ethylene Biosynthesis and Signaling Is Required for Rice Immune Response and Basal Resistance Against Magnaporthe oryzae Infection
}

\author{
Emily E. Helliwell, Qin Wang, and Yinong Yang \\ Department of Plant Pathology and Environmental Microbiology, and Huck Institutes of Life Sciences, Pennsylvania State \\ University, University Park, PA 16802, U.S.A.
}

Accepted 21 September 2016.

\begin{abstract}
Recent studies have suggested that ethylene enhances host resistance to fungal pathogen Magnaporthe oryzae, the causal agent of rice blast disease. Among the six 1-aminocyclopropane-1carboxylic acid synthase genes in rice, OsACS1 and $O$ sACS2 are induced within $24 \mathrm{~h}$ of inoculation by $M$. oryzae. This induction occurs simultaneously with an increase in ethylene production that is noticeable $12 \mathrm{~h}$ postinoculation. The purpose of this study was to examine the dynamics of ethylene production and signaling in wild type and RNA interference-mediated suppression lines deficient in ethylene production (acs2) or signaling (eil1) after challenge with $M$. oryzae as well as fungal cell-wall elicitors. Ethylene-insensitive mutant lines show an attenuated basal defense response including lower basal expression of the genes encoding a chitin-binding receptor, pathogenesis-related (PR) proteins, and the enzymes involved in the synthesis of diterprenoid phytoalexins, a reduction on early hypersensitive response (HR)-like cell death, and reduced incidence of callose deposition. Ethylene-deficient mutants showed an intermediate phenotype, with a significant reduction in expression of defense-related genes and callose deposition, but only a slight reduction in HRlike cell death. As a result, all ethylene-insensitive mutants show increased susceptibility to $M$. oryzae, whereas the ethylenedeficient lines show a slight but less significant increase in disease severity. These results show that ethylene signaling and, to some extent, ethylene production are required for rice basal resistance against the blast fungus Magnaporthe oryzae.
\end{abstract}

In response to microbial infection, innate immunity or basal resistance response is initiated in plants by host recognition of a conserved molecular entity known as a pathogen or microbeassociated molecular pattern (PAMP or MAMP). Host plants recognize PAMPs or MAMPs through the action of pattern

Sequence data has been deposited under the following accession numbers: OsACS1, AK071011; OsACS2, AK064250; OsEIN2a, AAL83627; OsEIN2b, AC093017; and OsEIL1, DQ153245.

Current address for E. E. Helliwell: Center for Genome Research and Biocomputing, and Department of Botany and Plant Pathology, Oregon State University, Corvallis, OR 97331, U.S.A.

Corresponding author: Y. Yang; E-mail: yuy3@psu.edu;

Telephone: +1.814.867.0324; Fax: +1.814.863.7217.

*The $\boldsymbol{e}$-Xtra logo stands for "electronic extra" and indicates that four supplementary figures and one supplementary table are published online.

(c) 2016 The American Phytopathological Society recognition receptors (PRRs), which results in PAMP-triggered immunity (PTI). PTI represents an evolutionarily conserved, ubiquitous form of basal resistance (Niks and Marcel 2009) that has received much attention recently, due to its potential to be used in molecular breeding for engineering broad-spectrum disease resistance (Gust et al. 2010). Hallmarks of PTI include cell membrane depolarization, rapid ion fluxes, generation of reactive oxygen species, activation of signal transduction pathways, synthesis of phytoalexins, and, in some cases, programmed cell death (Schwessinger and Ronald 2012).

In many pathosystems, plant exposure to biotic stresses results in the synthesis of defense-related hormones, such as salicylic acid, jasmonic acid, and ethylene. A generalized model suggests salicylic acid signaling as being associated with resistance to biotrophic pathogens, whereas jasmonic acid and ethylene signaling have been correlated with resistance to hemobiotrophic and necrotrophic pathogens (Hammond-Kosack and Jones 1996). Ethylene is a gaseous phytohormone that plays a variety of roles in plant growth and development as well as biotic and abiotic stress responses. The developmental roles include seed dormancy and germination, root architecture, flowering, fruit ripening, and senescence. Its roles in biotic and environmental stresses are complex and often contradictory depending on the specific plant-microbe interaction. In accordance with its classification as a defense and stress-response hormone, ethylene has been implicated as a resistance factor in a number of pathosystems. For example, application of exogenous ethylene results in increased expression of pathogenesis-related $(P R)$ genes, reinforcement of the cell wall, and an increase in antimicrobial phenylpropanoids in rice (Agrawal et al. 2001). Transgenic studies involving one or both ethylene-deficient or ethyleneinsensitive lines have further shown the roles of ethylenemediated resistance in Arabidopsis against the fungal pathogen Alternaria brassicicola (Anderson et al. 2004), in tobacco against A. brassicicola, Botrytis cinerea, Fusarium oxysporum, Pythium spp., and Xanthomonas campestris (Geraats et al. 2003), and in soybean against Septoria glycines and Phythopthora sojae (Hoffman et al. 1999). In contrast to these examples, ethylene has been known to cause an antagonistic effect on host resistance, for example, in the Arabidopsis-Pseudomonas syringae interaction (Chen et al. 2009) and in the interaction of rice and Cochliobolus miyabeanus (De Vleesschauwer et al. 2010).

In determining whether ethylene acts as a positive or negative mediator in a particular pathosystem, it is important to know the effects that induction of its biosynthetic and signaling pathways has on the host. One of the most ambiguous roles of ethylene and its effects on disease is cell death and symptom development. A number of studies have shown that ethylene synthesis 
is required for programmed cell death, including the hypersensitive response (HR) (Asai et al. 2002; Gallie and Young 2004; Lund et al. 1998; Moeder et al. 2002; Overmyer et al. 2003). In the case of two bacterial pathogens, Pseudomonas syringae and Xanthomonas spp., ethylene is shown to be necessary for symptom development in Arabidopsis and tomato, respectively (Bent et al. 1992; Lund et al. 1998). In some cases, it has been shown that pathogen effector proteins will manipulate hormone biosynthetic and signaling pathways to facilitate the infection process. This is seen in the tomato- $P$. syringae pv. tomato pathosystem, in which the bacterial effector proteins AvrPto and Avr PtoB activate expression of genes involved in the ethylene biosynthetic pathways, specifically LeACOI and LeACO2 (Cohn and Martin 2005; Jia and Martin 1999). 1-Aminocyclopropane-1-carboxylic acid (ACC) oxidase (ACO)knockout tomato mutants showed a lack of symptom development after inoculation by two bacterial pathogens (Xanthomonas campestris pv. vesicatoria and P. syringae pv. tomato) and one fungal pathogen (Fusarium oxysporum f. sp. lycopersici) (Lund et al. 1998).

Ethylene biosynthesis starts with the conversion of methionine to $S$-adenosyl-L-methionine (AdoMet) by the enzyme Met adenosyl-L-methionine synthetase (AdoMet synthetase). AdoMet is then converted into the ethylene precursor ACC by the enzymatic activity of ACC synthase (ACS) (Yang and Hoffman 1984). This is the first committed step of the pathway and is, therefore, considered to be the rate-limiting step (Chae and Kieber 2005). The final step involves the conversion of ACC into ethylene and hydrogen cyanide by the activity of ACC oxidase (ACO) (Lim et al. 2007). Once ethylene is produced, it is perceived by its receptors (e.g., five known receptors in Arabidopsis, ETR1, ETR2, ERS1, ERS2, and EIN4), which results in the inhibition of CTR1, a Raf-like mitogen-activated protein kinase kinase kinase that normally phosphorylates EIN2 in the absence of ethylene (Ju et al. 2012). This leads to dephosphorylation and proteolytic cleavage of EIN2 and nuclear translocation of its carboxyl-terminal fragment (Qiao et al. 2012), which in turn allows EIN3/EIL1 to activate various ethylene response factors (ERFs) (Alonso et al. 1999). ERFs activate various GCC-box genes, many of which encode PR proteins (Solano et al. 1998)

Studies done in the past few years have suggested that ethylene plays a positive role in resistance to rice blast disease, which is caused by the filamentous fungal pathogen Magnaporthe oryzae. Singh et al. (2004) showed that application of ethephon, a synthetic form of ethylene, resulted in a reduction of blast incidence in field conditions. Iwai et al. (2006) studied the transcription of ethylene biosynthetic genes from the ACS and $A C O$ families after inoculation by virulent and avirulent isolates of $M$. oryzae. At least two of six $A C S$ genes in rice are induced by $M$. oryzae (OsACS1 and OsACS2). Both OsACS1 and $O S A C S 2$ were transiently induced at $24 \mathrm{~h}$ postinoculation (hpi), followed by a second, high induction of only OsACS2 at $48 \mathrm{hpi}$ in a rice cultivar containing the blast resistance gene $P i$ - $i$, suggesting that ethylene biosynthesis plays a role in $P i-i$ mediated gene-for-gene resistance to $M$. oryzae (Iwai et al. 2006). Further work into $P i$-i-mediated specific resistance suggested that it was not ethylene itself but the ethylene biosynthetic pathway byproduct cyanide that inhibits $M$. oryzae infection and is responsible to enhance flavonoid production and $M$. oryzaeinduced HR (Seo et al. 2011). Cyanide and not ethylene as being responsible for ethylene-mediated resistance is somewhat contradictory to the results of Singh et al. (2004) and the studies using ethylene-insensitive rice mutants. Evidence for the role of the ethylene signaling pathway in blast resistance comes from work done using ethylene signaling suppression lines. Rice contains two OsEIN2-like genes, denoted OsEIN2a and OsEIN2b. Suppression of one of the homologs, OsEIN2b, resulted in higher susceptibility to $M$. oryzae without reduction in ethylene biosynthesis (Bailey et al. 2009). Likewise, suppression of the Arabidopsis EIN3 homolog OsEIL1 showed increased susceptibility to M. oryzae, which further suggests that ethylene signaling is required for blast resistance (Chen 2009; Mao et al. 2006).

The objective of this study was to examine the dynamics of both the ethylene biosynthetic and signaling pathways in response to $M$. oryzae infection and the fungal cell-wall elicitor and to clarify the role of ethylene biosynthesis and signaling in mediating basal or race-specific resistance, or both, using intact rice plants and cultured cells of ethylene-deficient (acs2) or ethyleneinsensitive (eill) transgenic lines. We have found that many hallmarks of basal resistance are attenuated in the ethyleneinsensitive mutants, including expression of PRR and PR genes, callose deposition, and HR-like cell death; as well as evidence of reduced membrane depolarization and suppression of phytoalexin biosynthetic genes. Subsequently, the ethylene-insensitive lines showed enhanced disease severity and fungal colonization after inoculation by $M$. oryzae. The ethylene-deficient mutants showed reduced expression of defense-related genes and an intermediate phenotype (with a slight increase in disease severity) in comparison with the nontransformed controls and ethylene-insensitive lines. These results suggest that ethylene biosynthesis and signaling is required for rice basal defense response.

\section{RESULTS}

\section{The ethylene biosynthetic pathway is triggered by both avirulent and virulent isolates of $M$. oryzae as well as by a fungal cell-wall elicitor.}

To examine whether ethylene is produced in both compatible and incompatible rice- $M$. oryzae interactions, 14-day-old seedlings of 'Katy', which carries the resistance $(R)$ gene $P i$ ta were spray-inoculated with either an avirulent (18-1) or a virulent (18-1/2) isolate of $M$. oryzae (IC17 pathotype) (Harp and Correll 1998). The virulent isolate lost AvrPi-ta, rendering it compatible with cultivars containing the $\mathrm{Pi}$-ta resistance gene. As shown in Figure 1A, ethylene levels increased between 0 and $24 \mathrm{hpi}$, peaking at $24 \mathrm{hpi}$, and decreasing back to basal levels at $72 \mathrm{hpi}$, in both compatible and incompatible interactions. In the compatible interaction, there is an increase of ethylene at $96 \mathrm{hpi}$, possibly due to extensive tissue damage and necrosis caused by the virulent isolate at this time point. A water-inoculated control was included to show that the ethylene production is not due to the changes of environmental conditions after inoculation. These results are also mirrored in our previous study, which shows an increase in ethylene production in the compatible 'Kitaake' after inoculation with $M$. oryzae 18-1 (Helliwell et al. 2013). The results of this experiment show that ethylene is produced rapidly after inoculation, outside of the gene-for-gene interaction, but increases drastically in the compatible interaction in correlation with the appearance of symptomatic lesions.

The rate-limiting step of the ethylene biosynthetic pathway is the conversion of AdoMet to the ethylene precursor ACC by ACS. As mentioned previously, two of the OsACS genes, OsACS1 and OsACS2, are induced in the Pi-i $R$ gene background (Iwai et al. 2006). Quantitative reverse transcriptionpolymerase chain reaction (qRT-PCR) demonstrated that both OsACS1 and OsACS2 were upregulated starting at $12 \mathrm{hpi}$, peaking at $24 \mathrm{hpi}$, in response to both avirulent and virulent isolates of M. oryzae (Fig. 1B and C). The expression of both genes were reduced at $48 \mathrm{hpi}$; however, the avirulent interaction shows a decrease of more magnitude. The expression of OsACS 1 mirrors that of the basal level by $96 \mathrm{hpi}$, but OsACS 2 remains elevated 72 and 96 hpi in the virulent interaction. 
As $O s A C S 1$ and $O s A C 2$ are induced in both compatible and incompatible interactions, we hypothesized that ethylene biosynthesis occurred as part of a basal defense reaction. To see if these genes could be induced by PAMPs, M. oryzae cellwall extract was added to $2 \mathrm{~g}$ of 'Kitaake' cell cultures to a concentration of $15 \mathrm{ng} / \mathrm{ml}$ of glucose equivalent. qRT-PCR showed that, relative to a mock-inoculated sample (denoted "0"), transcripts of both OsACS1 and OsACS2 peaked at $3 \mathrm{~h}$ posttreatment, with 25 - and 17-fold increases, respectively, and remained elevated up to the last time point at $24 \mathrm{~h}$ postelicitation (Figs. 1D and E).

\section{Generation of ethylene-deficient transgenic rice} by RNA interference (RNAi)-mediated suppression of $O s A C S$ expression.

In order to gauge the effect of suppressing $M$. oryzaeinduced ethylene synthesis, OsACS2 was chosen to knock down, due to the fact that it is induced to a higher degree than OsACS1 after inoculation with $M$. oryzae. An $O s A C S 2$-RNAi construct was created by inserting a cDNA fragment from the coding region, in both forward and reverse direction, into the pANDA vector, which contains a constitutive ubiquitin promoter (Supplementary Fig. S1A). The Agrobacterium-mediated rice transformation with the RNAi construct yielded five independent lines, with 17 plants total. Successful suppression of OsACS2 was determined by measuring $O s A C S 2$ transcript relative to control 'Kitaake', using qRT-PCR, and by measuring ethylene production with a gas chromatograph. The results showed various levels of OsACS2 knockdown and ethylene production among transgenic plants. Three independent lines were selected to advance to further generations: OsACS2-RI-1 (denoted acs2-1) and OsACS2-RI-2 (acs2-2), which showed the highest reduction in expression of OsACS2 and ethylene production, and OsACS2-RI-4 (acs2-4), which showed an intermediate (approximately 50\%) reduction in expression of OsACS2 and ethylene production. The same two parameters
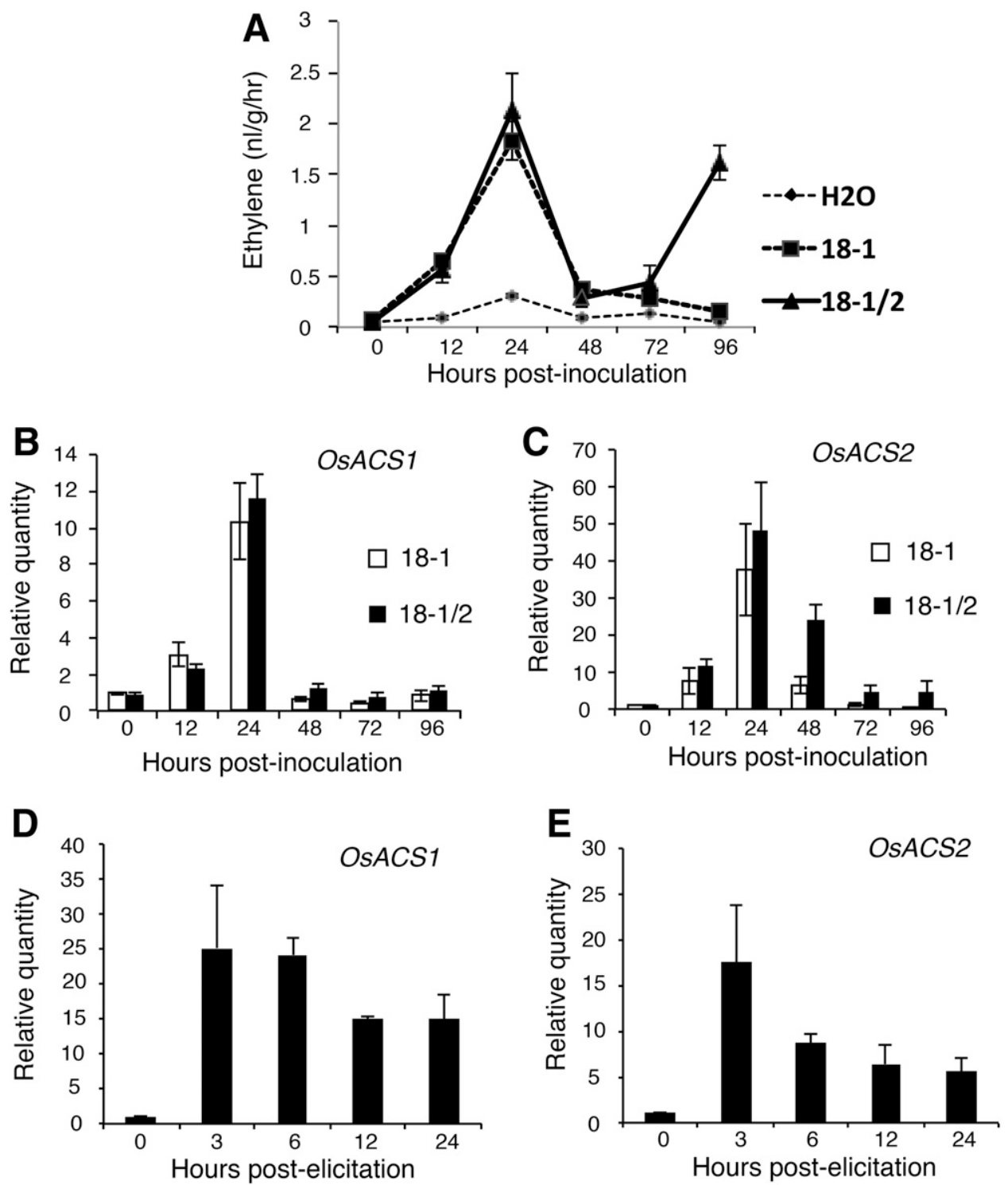

Fig. 1. Production of ethylene in rice in response to Magnaporthe oryzae infection or fungal elicitor treatment. A, Measurement of ethylene levels in 'Katy' (Pi-ta/Pi-ta) after inoculation with an avirulent (18-1) or virulent (18-1/2) isolate of M. oryzae (IC17 pathotype) (Harp and Correll 1998). B, Relative quantity of OsACS1 mRNA in 'Katy' after inoculation with an avirulent (18-1) or virulent (18-1/2) isolate of M. oryzae. C, Relative quantity of OsACS2 mRNA in 'Katy' after inoculation with an avirulent (18-1) or virulent (18-1/2) isolate of $M$. oryzae. D, Relative quantity of OsACS1 mRNA in 'Kitaake' cell cultures treated with $15 \mathrm{ng}$ of M. oryzae cell-wall elicitors per milliliter. E, Relative quantity of OsACS2 mRNA in 'Kitaake' cell cultures treated with $15 \mathrm{ng}$ of M. oryzae cell-wall elicitors per milliliter. All bars and points represent three independent biological replicates, with leaves from six plants or $2 \mathrm{~g}$ of cells per replicate. 
were used to test plants in the T2 generation. Both acs $2-1$ and acs $2-2$ showed higher than an $80 \%$ reduction in both $O s A C S 2$ expression and ethylene production, and the intermediate acs 2-4 line showed a $50 \%$ reduction in OsACS 2 expression and a $40 \%$ reduction in ethylene production. These results show that suppression of OsACS2 is effective and stable through at least two generations in OsACS2-RI lines.

OsACS2-RI lines show a dwarf phenotype, delayed maturity, and a reduced seed set.

OsACS2-RI lines acs2-1 and acs2-2 were grown in greenhouse conditions to seed along with control 'Kitaake' to observe any phenotypic differences. It was apparent that both recombinant inbred lines showed a dwarf phenotype in the T1 generation (Supplementary Fig. S2A). This was confirmed by growth curve analyses calculated in the $\mathrm{T} 3$ generation, as both OsACS2-RI lines exhibited about a $45 \%$ reduction in height after 10 weeks. In addition to this, the OsACS2-RI lines showed a delay in leaf senescence and maturity, lagging behind control 'Kitaake' by as much as 2 weeks, starting at the flowering stage in acs 2-1. In acs2-2, the difference does not become apparent until maturity stage. Lastly, both OsACS2-RI lines showed a drastic reduction in seed set, with an average of seven to eight seeds per panicle, as opposed to about 38 seeds per panicle in control 'Kitaake'. This combination of phenotypes is reminiscent of ethylene-insensitive OsEIN2b-RI and OsEIN2a+b-RI lines (Chen 2009) and serves as evidence that these two OsACS2-RI lines show an ethylene-deficient phenotype.

OsACS2-RI lines show reduced expression of ethylene biosynthetic and signaling genes as well as decreased ethylene production after $M$. oryzae infection.

qRT-PCR was used to measure the expression of OsACS2 as well as $O s E R F 1$, which is a transcription factor involved in the
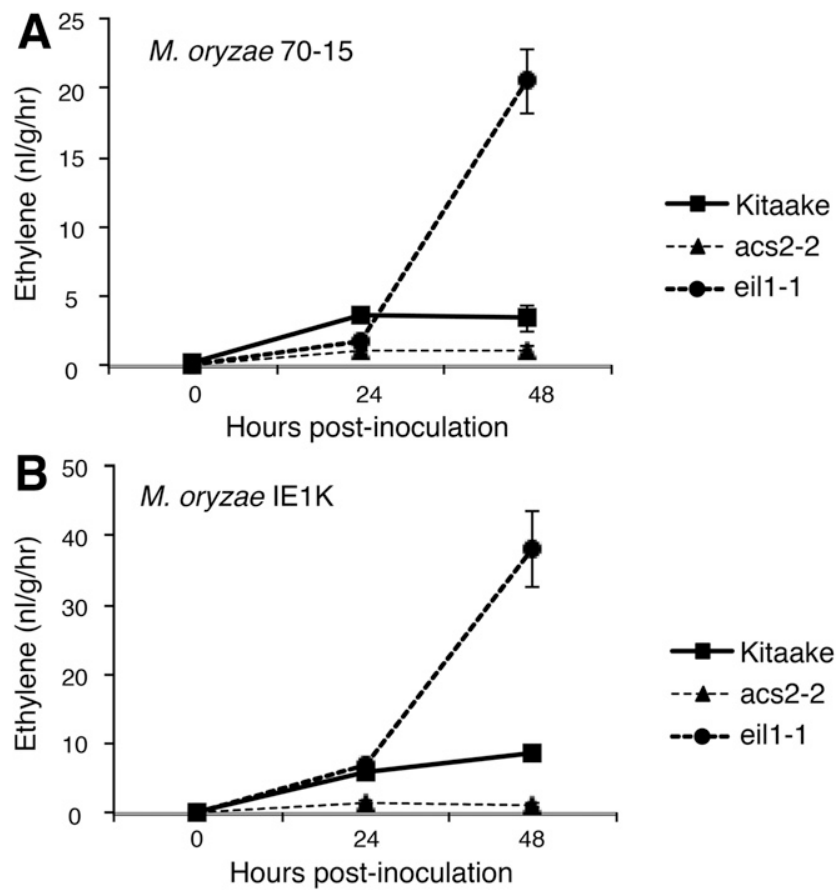

Fig. 2. Ethylene production in ethylene-deficient and -insensitive rice lines after inoculation with Magnaporthe oryzae. A, Nontransformed 'Kitaake' and ethylene-deficient (acs2-RI) and -insensitive (eil1-RI) lines inoculated with moderately virulent $M$. oryzae isolate 70-15. B, Nontransformed 'Kitaake', acs2-RI, and eil1-RI lines inoculated with highly virulent M. oryzae isolate IE1K. Points are the average of two biological replicates, with leaves pooled from six different plants per replicate. ethylene signaling pathway. The purpose of measuring these genes is twofold: first, to see if the knockdown of OsACS2 in the transgenic lines is effective after the fungal inoculation, and second, to see if this reduction in ethylene biosynthesis has an effect on downstream factors in the ethylene signaling pathway. As expected of OsACS2-RI lines, there was a significant reduction in the pathogen-induced activation of $O s A C S 2$ at $48 \mathrm{~h}$ after inoculation $(\mathrm{F}=10.19 ; P<0.0001)$ (Supplementary Fig. $\mathrm{S} 3 \mathrm{~A})$. Along these same lines, the inoculated OsACS2-RI lines showed a significant reduction in the induction of OsERF1 $(\mathrm{F}=$ 5.53; $P=0.0005)$. These results show that suppression of OsACS2 has an effect on the ethylene signaling pathway after inoculation with $M$. oryzae. Similarly, the expression of various $P R$ genes was measured in $M$. oryzae-inoculated OsACS2-RI lines. As described previously, the ethylene signaling pathway is involved in the transcription of various $P R$ genes whose promoters contain a GCC motif (GCC-box genes) that is regulated by OsERF1 (Agrawal et al. 2001). Both acs2-1 and acs2-2 showed reduced induction of chitinase $(P R 3)(\mathrm{F}=2.06 ; P=$ $0.088)$ and $P R 5(\mathrm{~F}=8.64 ; P<0.0001)$ at 48 hpi. The reduction in $O s E R F 1$ and $P R$ gene expression serves as evidence that i) the ethylene signaling pathway is attenuated in OsACS2-RI lines and ii) suppression of ethylene biosynthesis may have a negative effect on rice defense response.

\section{Ethylene-deficient and -insensitive rice lines show altered} ethylene production after inoculation with M. oryzae.

$M$. oryzae-induced ethylene production was measured in OsACS2-RI lines along with nontransformed 'Kitaake' and an ethylene-insensitive line, OsEIL1-RI. OsEIL1-RI is a transgenic RNAi line, previously developed in our lab, that suppresses OsEIL1 (Chen 2009), which encodes a member of the EIN3/EIL family of transcription factors (Mao et al. 2006). Previous work done in our lab shows that OsEIL1-RI (denoted eill-1) lines have expression of OsACS2 similar to that of nontransformed 'Kitaake' at basal levels as well as after inoculation with $M$. oryzae but decreased expression of downstream ethylene-responsive genes, including $O s E R F 1$ and $O s P R 5$. Ethylene-deficient line acs 2-2 showed lower basal levels of ethylene, with about $10 \%$ of the ethylene production of nontransformed 'Kitaake'. This trend continues 24 and 48 hpi with moderately virulent $M$. oryzae isolate $70-15$, with both ethylene-deficient lines showing decreased ethylene production as compared with 'Kitaake' as well as eill-1, which shows a significant increase in ethylene production $48 \mathrm{~h}$ after inoculation (Fig. 2A). This experiment was repeated using a highly virulent isolate of $M$. oryzae, IE1K (TM2). The results are consistent to that was seen after inoculation with isolate 70-15. The ethylene-deficient line acs 2-2 showed decreased ethylene production, as compared with nontransformed 'Kitaake' and eill-1, at both 24 and 48 hpi (Fig. 2B). The results of these experiments demonstrate that production of ethylene induced by M. oryzae is reduced in the OsACS2-RI lines.

\section{Ethylene biosynthesis and signaling is required} for induction of rice genes involved in basal defense and phytoalexin biosynthesis.

Recent studies on the PRR FLS2 in Arabidopsis indicate a role of ethylene biosynthesis and signaling in perception of PAMP elicitors (Boutrot et al. 2010; Mersmann et al. 2010). Previous work done with rice cultures has identified a transmembrane PRR, called chitin elicitor-binding protein (CEBiP) that, as the name suggests, binds to chitin with high affinity (Kaku et al. 2006; Kishimoto et al. 2010). In this study, the expression of $C E B i P$ was measured in cultured cells of 'Kitaake', acs2-2, and eill-1 at various time points after treatment with $30 \mathrm{ng}$ of $M$. oryzae cell-wall elicitor per milliliter. In 
nontransformed 'Kitaake', there is a 17-fold increase in $C E B i P$ transcripts starting at $3 \mathrm{~h}$ postelicitation, which further increases to 58 -fold at $6 \mathrm{~h}$ posttreatment. In comparison, there is a significant reduction of $C E B i P$ expression in both basal (untreated, denoted $0 \mathrm{~h}$ ) and elicitor-treated acs $2-2$ and eill-1 lines, starting at 0.07 -fold and 0.18-fold, increasing to 1.3 - and 2.7 -fold at $6 \mathrm{~h}$ relative to nontransformed 'Kitaake' (Fig. 3A). The results of this experiment suggest that ethylene biosynthesis and signaling is involved in PTI and rice basal defense, as it is required for expression of the PRR gene CEBiP.

As ethylene-deficient and -insensitive cell lines showed decreased activation of an elicitor-inducible PRR gene, CEBiP, we suspected that these lines would also show decreased expression of rice $P R$ and phytoalexin biosynthetic genes, as overexpression of $C E B i P$ was shown to increase the expression of these defense-related genes (Kaku et al. 2006; Kishimoto et al. 2010). qRT-PCR analysis has shown that the expression of phenylalanine ammonia lyase (OsPAL) in 'Kitaake' control plants peaked with a 69 -fold increase at $3 \mathrm{~h}$ postelicitation and, then, dropped by $6 \mathrm{~h}$ to a 8.6 -fold increase over the basal level (Fig. 3B). Expression of $P A L$ in acs $2-2$ remained low until $6 \mathrm{~h}$ posttreatment, in which its transcript level elevated to 20 -fold over the basal level. In contrast to both 'Kitaake' and acs2-2 lines, $P A L$ was not induced in elicited eill-1 cells (Fig. 3B). This trend of acs2-2 lines having an intermediate pattern of delayed and reduced induction of $P A L$ was echoed in the expression pattern of PR5 (Fig. 3C). PR5 was induced significantly in 'Kitaake' control plants, starting at $3 \mathrm{~h}$ postelicitation and peaking at $6 \mathrm{~h}$, with 4.5 - and 13-fold increases over the basal level. Comparatively, acs 2 -2 lines show a slight induction of PR5 (1.8-fold) within $6 \mathrm{~h}$ of elicitation that mirrors 'Kitaake' but to a significantly lower degree over the basal level. eill-1 cells do not show any induction of PR5 within $6 \mathrm{~h}$ of elicitation. These results suggest that defection of either ethylene biosynthesis or signaling in rice compromises the induction of defense-related genes by the fungal elicitor.

Rice cells treated with elicitors respond by producing phytoalexins, which are secondary metabolites with antimicrobial properties. To see if phytoalexin production could be compromised in elicited cell cultures of ethylene-deficient and -insensitive rice, we measured the expression of two genes involved in momilactone biosynthesis, which has been shown to be highly correlated with production of momilactones in previous studies involving elicited rice cells (Kishimoto et al. 2010; Okada et al. 2009; Shimura et al. 2007). The first of these two genes, OsKSL4, is involved in the cyclization of the phytoalexin precursor geranylgeranyl diphosphate to yield syn- and ent- forms of copalyl diphosphate, which is an early reaction in the momilactone biosynthetic pathway (Otomo et al. 2004; Sakamoto et al. 2004). In this study, there was a massive induction of OsKSL4 in elicitor-treated nontransformed 'Kitaake' cells at $3 \mathrm{~h}$ posttreatment, with a 3,970-fold increase relative to the basal level that rose further at $6 \mathrm{~h}$ posttreatment to a 31,301fold increase (Fig. 3D). OsKSL4 is also expressed at 3 and $6 \mathrm{~h}$ posttreatment in ethylene-insensitive eill-RI cells but at a significantly reduced extent in comparison with the nontransformed basal level, with a 1,308-fold and 5,925-fold increase, respectively.

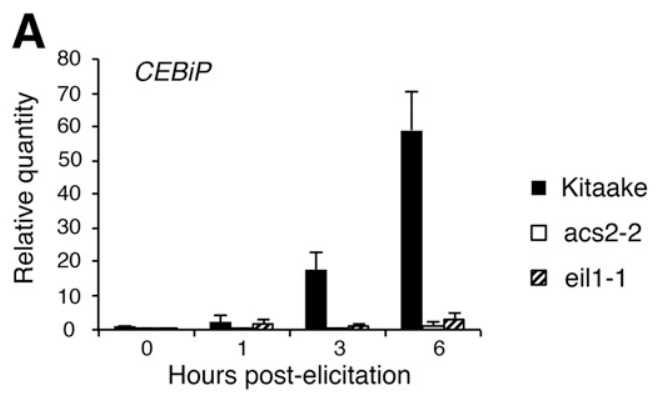

B
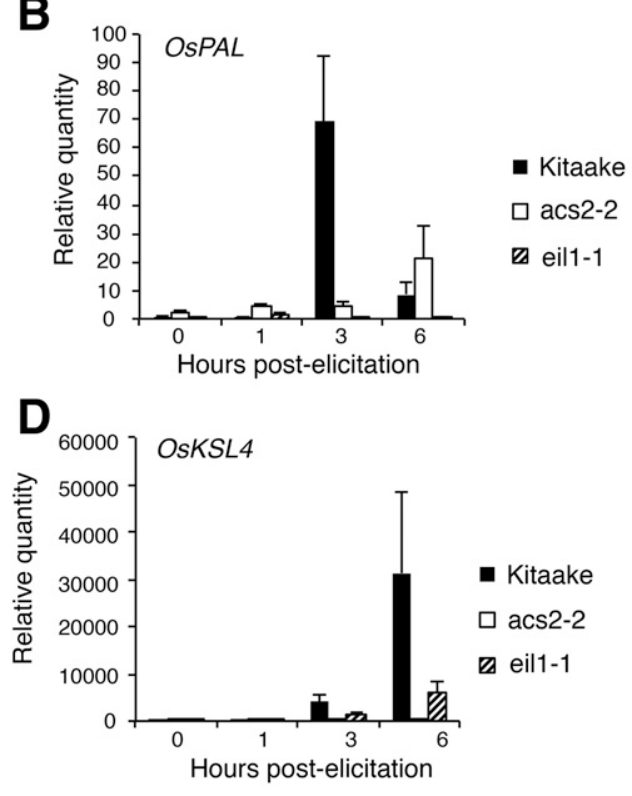

C

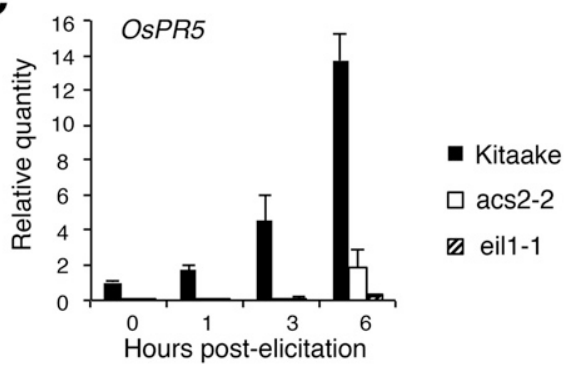

E

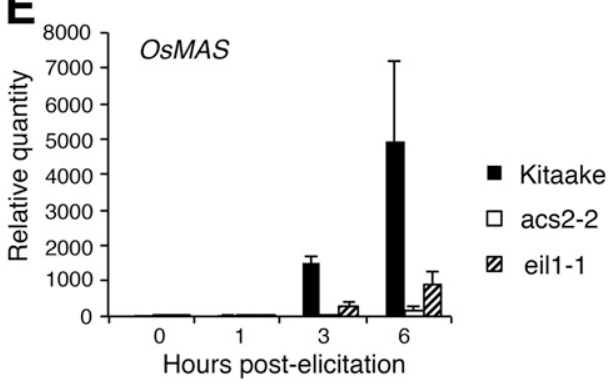

Fig. 3. Relative expression of rice genes involved in basal resistance and phytoalexin biosynthesis in the elicitor-treated cell cultures of 'Kitaake', acs2-RI, and eill-RI lines. A, CEBiP; B, OsPAL; C, OsPR5; D, OsKSL4; and E, OsMAS. Bars represent two independent biological replicates of cell cultures treated with $15 \mathrm{ng}$ of Magnaporthe oryzae cell-wall elicitors per milliliter. 
There is a much weaker induction of OsKSLA in ethylene-deficient acs2-2 cells at $6 \mathrm{~h}$ postelicitation (303-fold) compared with the nontransformed basal level. These results mirror that of OsMAS expression. OsMAS codes for a dehydrogenase, which is involved in the downstream conversion of $3 \beta$-hydroxy- $9 \beta \mathrm{H}$-pimara-7,15dien-19,6 $\beta$-olide to momilactone A (Okada et al. 2009; Shimura et al. 2007). Like OsKSLA, OsMAS exhibits a 1,490-fold induction by $3 \mathrm{~h}$ posttreatment with the fungal cell-wall elicitor and rises to 4,923-fold increase over the basal level at $6 \mathrm{~h}$ in nontransformed 'Kitaake' cells (Fig. 3E). Ethylene-signaling mutant eill-1 cells also show increased expression of OsMAS at 3 and 6 hpi to 310and 897-fold increase, but the relative amount of transcripts is significantly lower than that of 'Kitaake'. Ethylene-deficient acs22 cells show a relatively slight induction of OsMAS expression at 3 and $6 \mathrm{~h}$ postelicitation with a respective 31- and 174-fold increase, but it is marginal compared with nontransformed 'Kitaake'. The results of these experiments echo the expression patterns of $C E B i P$ and $P R$ genes and further suggest that ethylene production and signaling are required for induction of rice genes involved in basal resistance.

\section{Ethylene-insensitive cell cultures show} reduced proton flux in response to elicitation.

A very early response to PAMP elicitation is membrane depolarization, followed by rapid ion fluctuations driven by elicitor-induced inhibition of the membrane-bound $\mathrm{H}^{+}$-ATPase. A good method of monitoring transmembrane proton $\left(\mathrm{H}^{+}\right)$flux in response to elicitation is by measuring the $\mathrm{pH}$ of culture
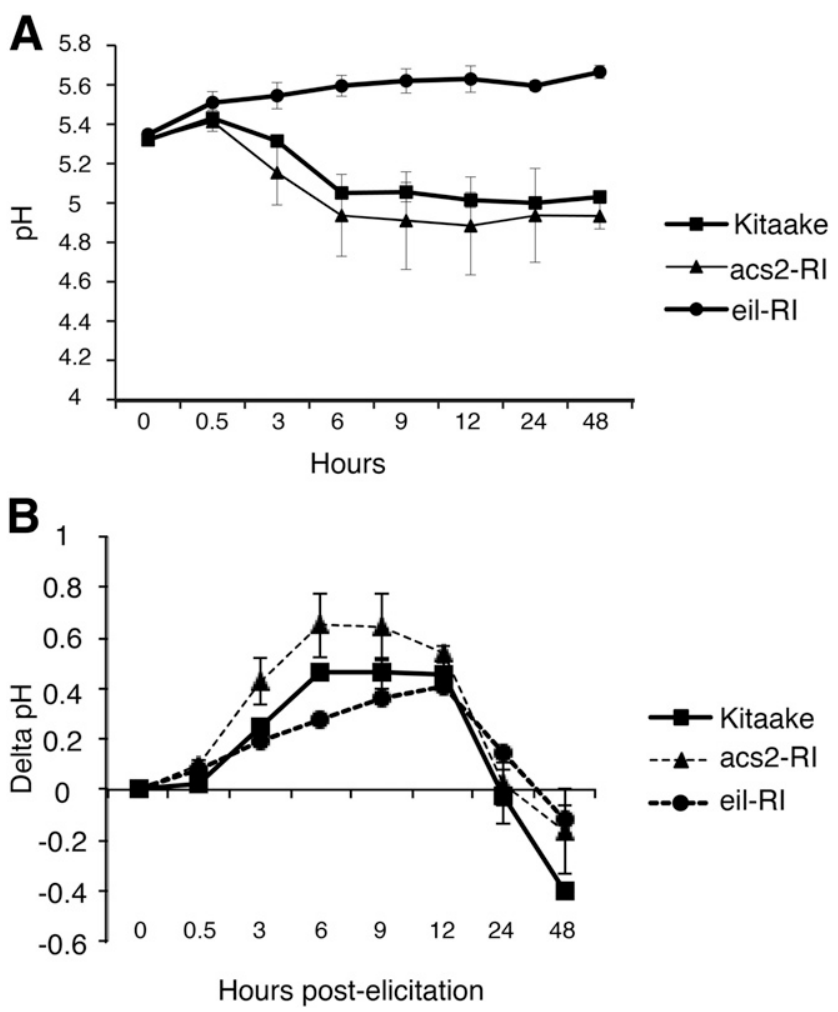

Fig. 4. Changes in $\mathrm{pH}$ of bathing media in mock- and elicitor-treated cell cultures. A, Changes in $\mathrm{pH}$ of bathing media after addition of nontransformed 'Kitaake', ethylene-deficient acs2-RI, and ethylene-insensitive eil1-RI cell cultures. $\mathbf{B}$, The differences in $\mathrm{pH}$ of bathing media between water- and elicitor-treated nontransformed 'Kitaake', ethylene-deficient (acs2-RI), and ethylene-insensitive (eil1-RI) cell lines. Each indicator represents the $\mathrm{pH}_{\text {elicited }}-\mathrm{pH}_{\text {mock }}$. Points represent the average of three independent biological replicates. All samples were treated with either $30 \mathrm{ng}$ of $M$. oryzae cell-wall elicitor per milliliter or an equal volume of sterile deionized water. media after treatment of cell cultures with elicitors (Amborabé et al. 2008). To examine the effect of suppressing ethylene biosynthesis and signaling pathways on elicitor-induced membrane depolarization, ethylene-deficient (acs2-2), ethylene-insensitive (eil1-1), and nontransformed 'Kitaake' cell cultures were treated with either $30 \mathrm{ng}$ of cell-wall elicitor per milliliter or an equal volume of sterile deionized water, and the $\mathrm{pH}$ of the culture fluid was measured within $48 \mathrm{~h}$. The results shown in Figure 4A indicate the raw $\mathrm{pH}$ values of water-treated cell cultures. After the addition of $2 \mathrm{~g}$ of cells to fresh media, there is a rapid drop $(<3 \mathrm{~h})$ to about $\mathrm{pH} 5$, followed by a negligible change in $\mathrm{pH}$ for the remainder of the experiment. In contrast, the $\mathrm{pH}$ of the culture media remains stable after addition of the ethyleneinsensitive eill-1 cells. The values indicated in Figure 4B show the difference in $\mathrm{pH}$ between elicited samples and the corresponding mock-treated samples at each time point. The overall result resembles an S-shaped curve, as the net change in $\mathrm{pH}$ increases and then decreases beyond the baseline into the negative range. This represents the culture media becoming more alkaline, representing a movement of protons into the cytosolic spaces, followed by an acidification representing cell death (Elmore and Coaker 2011), starting between $12 \mathrm{~h}$ to the final time point at $48 \mathrm{~h}$ postelicitation. There was a difference in $\mathrm{pH}$ for all lines starting at $0.5 \mathrm{~h}$ postelicitation, as alkalinization of the culture media occurs in the elicited samples. The patterns in alkalinization of culture media are similar between nontransformed 'Kitaake' and ethylene-deficient acs $2-2$ cells, which both peak at $6 \mathrm{~h}$ posttreatment, with about $\mathrm{a}+0.5$ to +0.6 change in $\mathrm{pH}$. At this time point, there is a significantly lower change in $\mathrm{pH}$ in the bathing media of eill-1 cells, which have a delayed peak at $12 \mathrm{~h}$ posttreatment, with an overall lower change in $\mathrm{pH}(+0.4)$ than the nontransformed 'Kitaake' and ethylene-deficient acs2-2 samples. There is a drop in $\mathrm{pH}$ starting at $12 \mathrm{~h}$ posttreatment for all cells. The culture media of nontransformed 'Kitaake' cell lines shows the most drastic acidification as compared with all of the ethylene mutants, which suggests less cellular membrane dysfunction and proton leakage in both mutant lines. These results show that the ethylene-insensitive line has reduced proton influx and less $\mathrm{pH}$ change in comparison with nontransformed and ethylene-deficient lines, both under the basal condition and after elicitation with the cell-wall elicitor.

\section{Ethylene-deficient and -insensitive rice lines exhibit reduced ion leakage, cell death, and callose deposition.}

Observational data suggested that both spot-inoculated ethylene-deficient and -insensitive mutants showed fewer HRlike lesions shortly after inoculation with $M$. oryzae. Therefore, we sought to quantify early cell death, for the purpose of examining the roles of ethylene biosynthesis and signaling in cell viability in response to elicitation. Evans blue staining was performed $24 \mathrm{~h}$ posttreatment with $15 \mathrm{ng}$ of fungal cell elicitors per milliliter, using a method similar to the one previously described (Delledonne et al. 2001). The ratio of dye intensity of elicited to ethanol-treated cells (assumed $100 \%$ cell death) was used to calculate the percentage of cell death due to elicitation (Fig. 5A). Compared with the nontransformed control 'Kitaake', which showed $67 \%$ cell death at $24 \mathrm{~h}$ postelicitation, ethylene-deficient $\operatorname{acs} 2-2$ lines showed a $20 \%$ reduction in cell death (about $45 \%$ cell death). Ethylene-insensitive eill-1 lines showed a drastic reduction in cell death, with less than $10 \%$ of cell mortality, in response to elicitation. This trend was also seen in ethylene-insensitive ein $2 a b-1$ mutant lines. Compared with corresponding nontransformed control 'Nipponbare' (which showed a relatively low $37 \%$ cell mortality), ein $2 a b-1$ cells showed a large 
reduction in cell death, with only about $5 \%$ cell mortality, in response to elicitation.

To quantify early cell death in response to inoculation by $M$. oryzae in ethylene-deficient and -insensitive lines, spotinoculated leaves were stained with Evans blue 2 to 3 days postinoculation (dpi). Three different isolates of $M$. oryzae were used, ranging from highly virulent (IE1K), moderately virulent (70-15), and avirulent (IA45). After inoculation by the two virulent isolates IE1K and 70-15, both nontransformed controls 'Kitaake' and 'Nipponbare' showed similar intensity of Evans blue stain as ethylene-deficient mutants acs $2-1$ and acs2-2 (Fig. 5B). In comparison, ethylene-insensitive mutants ein $2 a b-1$ and eill-1 showed reduced intensity of the stain. After inoculation with the avirulent isolate IA45, ethylene-deficient lines acs $2-1$ and acs $2-2$ showed an intermediate reduction in stain intensity, similar to ethylene-insensitive mutants ein $2 a b-1$ and eill-1. This implies that early cell death is reduced in ethylene-insensitive mutants, regardless of the virulence of the $M$. oryzae isolates used, which suggests, in turn, that ethylene signaling plays a positive role in HR-like cell death after infection of $M$. oryzae. In contrast, ethylene-deficient acs 2-2 lines show a varied phenotype, depending on the virulence of the isolate.

Another common method of examining cell death is to quantify ion leakage of elicited cells by measuring conductivity of the bathing media. The conductivity of the bathing media of ethylene-deficient and -insensitive cells treated with $30 \mathrm{ng}$ of $M$. oryzae cell-wall elicitor per milliliter was measured at various time points up to $24 \mathrm{~h}$ postelicitation. The differences of elicitor-treated cells and the corresponding untreated counterparts are shown in Figure 5C. The nontransformed controls 'Kitaake' and 'Nipponbare' showed a large increase in conductivity within $1 \mathrm{~h}$ of elicitation up to $6 \mathrm{~h}$ and leveled off up to $24 \mathrm{~h}$. In contrast, ethylene-deficient line acs 2-2 and ethyleneinsensitive lines ein $2 a b-1$ and eill-1 showed only a gradual increase in conductivity, with a low final reading at $24 \mathrm{~h}$ postelicitation. The results of these experiments again suggest that ethylene production and signaling both play roles in early cell death after elicitation; however, ethylene signaling may be more crucial.

Another hallmark of basal resistance is the deposition of callose, which makes the challenged plant cell more difficult for pathogen penetration. In this study, we wanted to see the separate effects of suppressing ethylene biosynthesis or signaling on callose deposition in response to $M$. oryzae. Leaves of nontransformed 'Kitaake', ethylene-deficient (acs2-2), and ethylene-insensitive (eill-1) lines were spot-inoculated with a constant volume and conidial concentration of $M$. oryzae 70 15. Leaves were stained 4 dpi with $0.1 \%$ aniline blue and were visualized using a fluorescent stereomicroscope with a UV filter. The number of foci within the centered one square millimeter frame of each inoculated spot was counted and averaged. Both acs2-2 and eill-1 lines showed a reduced number of callose deposition (14.1 and 18.7 foci per square millimeter, respectively) compared with nontransformed control 'Kitaake' (52.4 foci per $\mathrm{mm}^{2}$ ) (Fig. 6), which suggests that ethylene production and perception are required for callose deposition.
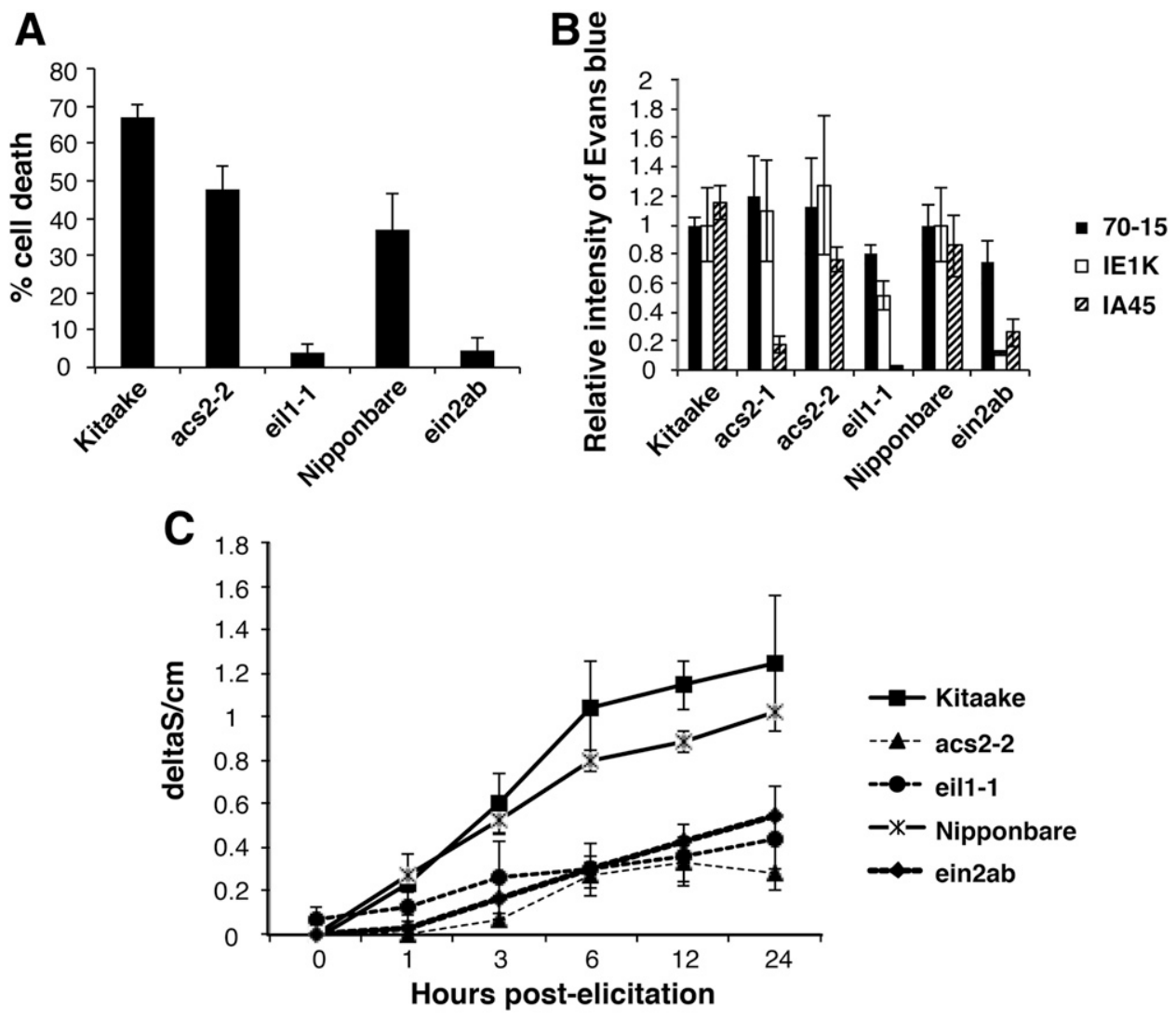

Fig. 5. Quantification of hypersensitive response-like cell death in nontransformed 'Kitaake' and ethylene-deficient and -insensitive lines. A, Measurement of cell death using $0.05 \%$ Evans blue staining at $24 \mathrm{~h}$ post-elicitation with $15 \mathrm{ng}$ of Magnaporthe oryzae cell-wall elicitor per milliliter. Results show the average of three independent biological replicates. Values represent percentage of cells as follows: $\%=\mathrm{A} 600_{\text {elicited }} / \mathrm{A} 600_{\text {ethanol-treated }}$ B, Measurement of cell death in M. oryzae spot-inoculated leaf disks with $0.25 \%$ Evans blue staining at $48 \mathrm{~h}$ postinoculation. Results show the average of three independent biological replicates, relative to the absorbance at $600 \mathrm{~nm}$ of 'Kitaake'. C, Quantification of ion leakage based on conductivity measurement of cell culture bathing media. Each dot represents the $\mathrm{S} / \mathrm{cm}_{\text {elicited }}-\mathrm{S} / \mathrm{cm}_{\text {mock }}$. Graph represents the average of two independent biological replicates. 
Ethylene-insensitive rice lines show enhanced susceptibility to $M$. oryzae infection.

To examine the roles of ethylene production and signaling in rice resistance to $M$. oryzae infection, ethylene-deficient lines acs 2-1, acs 2-2, ethylene-insensitive lines ein2ab-1, eill-1, and nontransformed controls 'Kitaake' and 'Nipponbare' were spray inoculated with a moderately virulent isolate of $M$. oryzae, 7015. The disease severity was scored one week later, based on lesion number and lesion size. There was not a significant difference in lesion number between nontransformed control 'Kitaake' and ethylene deficient acs2-1 and acs2-2 lines (Fig. 7A). However, there was a significant difference between nontransformed 'Kitaake' and ethylene-insensitive eill-1 lines. Likewise, there were significantly more lesions in the ethyleneinsensitive ein $2 a b-1$ line as compared with the corresponding nontransformed control 'Nipponbare' $(\mathrm{F}=8.64 ; P<0.001)$. This pattern was also seen in measurements of lesion size (Fig. 7B). One of the ethylene-deficient lines, acs $2-1$, did not show an average lesion size that was significantly different from nontransformed control 'Kitaake'; however, the second ethylenedeficient mutant, acs2-2, did, which suggests an intermediate phenotype. In contrast, the ethylene-insensitive lines ein $2 a b-1$ and eill-1 showed significantly larger lesions than the nontransformed control as well as the ethylene-deficient lines $(\mathrm{F}=$ 12.45; $P<0.0001)$.

To explore more subtle differences in resistance between nontransformed, ethylene-deficient, and ethylene-insensitive lines, a punch-inoculation method was used to deliver a known amount of conidia of a green fluorescent protein (GFP)-tagged isolate of M. oryzae on each leaf. The isolate used for this assay was Guy11, which carries a GFP gene driven by a constitutive promoter. Guy11-GFP was moderately virulent on 'Kitaake' and 'Nipponbare', similar to isolate 70-15. Disease severity was quantified $8 \mathrm{dpi}$, using two methods. First, the size of necrotic lesions was measured (Supplementary Fig. S4A), and second, lesions were viewed under a fluorescence stereomicroscope with a GFP filter and the program ImageJ was used to measure the area of viable (fluorescent) $M$. oryzae at each inoculation point. There was a significant difference in lesion size between the nontransformed 'Kitaake' and all ethylene-deficient and insensitive lines. However, GFP-tagged M. oryzae show a different result, as two of three of the ethylene-deficient lines (acs2-1 and acs2-4) were not significantly different from nontransformed 'Kitaake', whereas one of the ethylene-deficient lines (acs2-2) and both of the ethylene-insensitive lines (eill-1 and eill-4) had significantly more viable fungal biomass. This suggests that the size of the resulting necrotic lesion does not necessarily correlate with the amount of viable fungi after one week of inoculation. Additionally, it is noteworthy that the ethylene-insensitive mutants but not all of the ethylene-deficient mutants showed a significant difference from the nontransformed 'Kitaake'. This further suggests that ethylene signaling is more critical for ethylene-mediated basal resistance.

\section{DISCUSSION}

Our experimental data show that ethylene biosynthesis plays a role in basal defense response; however, ethylene signaling is absolutely required for full basal defense signaling and subsequent resistance to M. oryzae. Recent studies in Arabidopsis

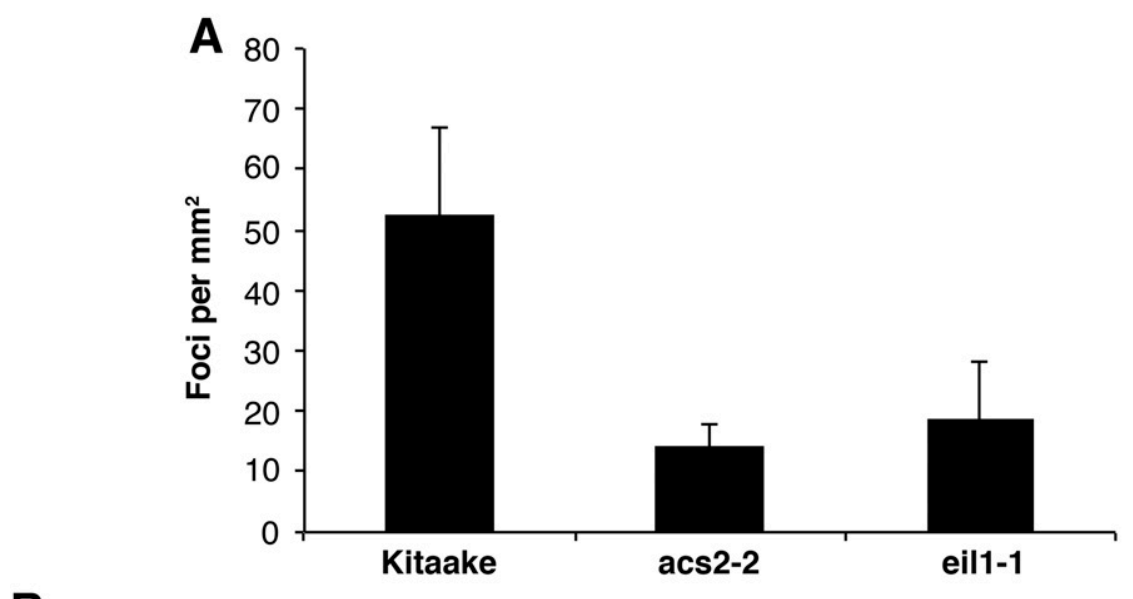

B

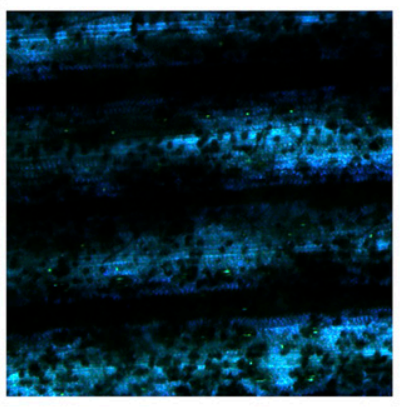

Kitaake

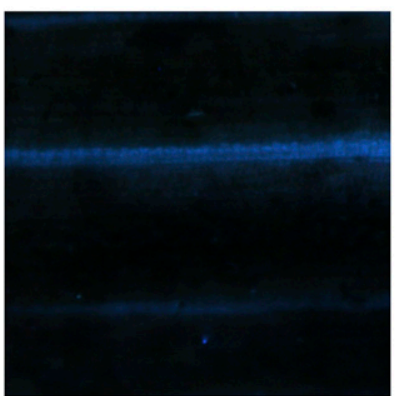

acs-2-2

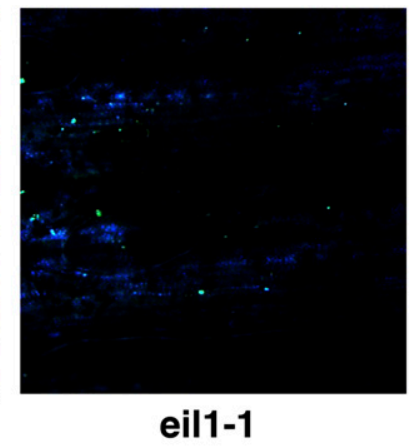

Fig. 6. Callose deposition in nontransformed and ethylene-deficient and -insensitive lines after spot inoculation with Magnaporthe oryzae. A, The average number of callose foci per square millimeter at the site of infection. B, Representative photographs of nontransformed 'Kitaake', ethylene-deficient acs2-RI, and ethylene-insensitive eill-RI lines (40x). All photographs were taken using a fluorescence stereomicroscope with a UV filter (280 to $320 \mathrm{~nm}$ ) at $40 \times$ magnification, 4 days postinoculation with M. oryzae 70-15. Bars represent the average of 16 samples per line. acs2-RI and eil1-RI bars each represent the average of two independent biological replicates. 
have linked ethylene production and signaling to transcriptional regulation of PRRs such as FLS2 (Boutrot et al. 2010; Mersmann et al. 2010). Rice has one homolog of $F L S 2$, which is induced by flagellin originating from the bacterial pathogen Acidovorax avenae (Pseudomonas avenae) (Takai et al. 2008). Acidovorax avenae causes brown stripe of rice and is able to colonize several monocotyledonous crops. Expression analysis with wild-type 'Kitaake', acs2-2, and eill-1 lines showed that OsFLS2 was not induced by $M$. oryzae elicitors, and basal levels of OsFLS2 were too low to get an accurate relative quantity using qRTPCR (data not shown). These results are not surprising, as flagellin, rather than a fungal elicitor, is probably involved in the induction of $O s F L S 2$. It is more likely that CEBiP, which binds to chitin, would be induced by fungal-derived molecules. Additional evidence for involvement of ethylene in expression of $C E B i P$ stems from microarray data from CEBiPRNAi lines. Compared with a nontransformed control, the CEBiP-RNAi lines show a downregulation of OsACS2 (listed as AK064250) (Kaku et al. 2006), suggesting a lack of production of ethylene as $C E B i P$ is suppressed. Our results show low basal levels of $C E B i P$ transcripts in the ethylene-deficient and -insensitive lines as compared with the nontransformed control as well as a low induction of $C E B i P$ after elicitation. It may be noteworthy to point out that, upon comparing induced expression of $C E B i P$ to the basal levels in the acs2-2 and eill-1 lines, the relative fold change may be as high as the change seen in nontransformed control 'Kitaake'. This suggests that induction of $C E B i P$ may occur by a different, unknown signal and that ethylene primarily affects the amount of its transcripts. To gauge the inducibility of $C E B i P$, a $2-\mathrm{kb}$ region upstream of the start codon was searched, using the Plant cis-acting regulatory DNA elements database (Higo et al. 1999). The search identified several putative cis-regulatory elements, including DRE/CRT (dehydration-responsive element/ C-repeat), W-box, and ABRE-like sequences. These motifs have been well-characterized to be involved in biotic and abiotic stress responses. It is likely that the expression of CEBiP is regulated by an ERF. If so, repression of ERF activation under the low basal level of the hormone or due to a defective signaling pathway, as seen in the OsACS2-RI and OsEIL1-RI lines, would result in low basal levels of $C E B i P$, as well as a lack of induction upon stimulation. Based on these findings, our results are consistent with the model suggested by Kaku et al. (2006), in which CEBiP serves as sort of a sensory mechanism dependent on ethylene signaling that would trigger a defense response to protect against pathogen invasion. It is also interesting to note that the CEBiP-RNAi lines show a downregulation of $O s A C S 2$ (Kaku et al. 2006). In our study, the OsACS2-RNAi lines show a downregulation of CEBiP. Therefore, the ethylene pathway appears to form a positive feedback loop with CEBiP to mediate rice PTI or basal resistance against microbial infection.

Previous studies show that many basal resistance-related changes are dependent on CEBiP (Kaku et al. 2006; Kishimoto et al. 2010; Shimizu et al. 2010). This, combined with the observation that $M$. oryzae-spot inoculated ethylene-deficient and -insensitive lines did not develop early HR-like lesions, suggests that the ethylene mutants displayed attenuated basal resistance. To further investigate this claim, we examined the expression patterns of genes involved in production of phenypropanoid (OsPAL), antimicrobial proteins (OsPR5), and of phytoalexins (OsKSLA and OsMAS). The ethylene-deficient

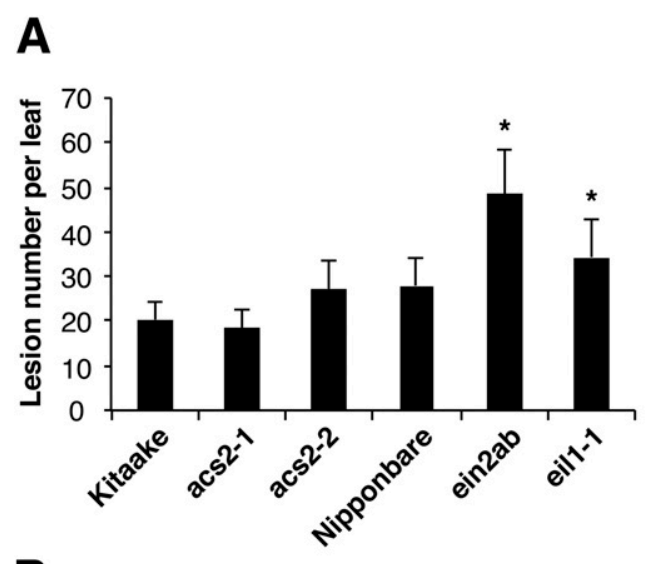

C
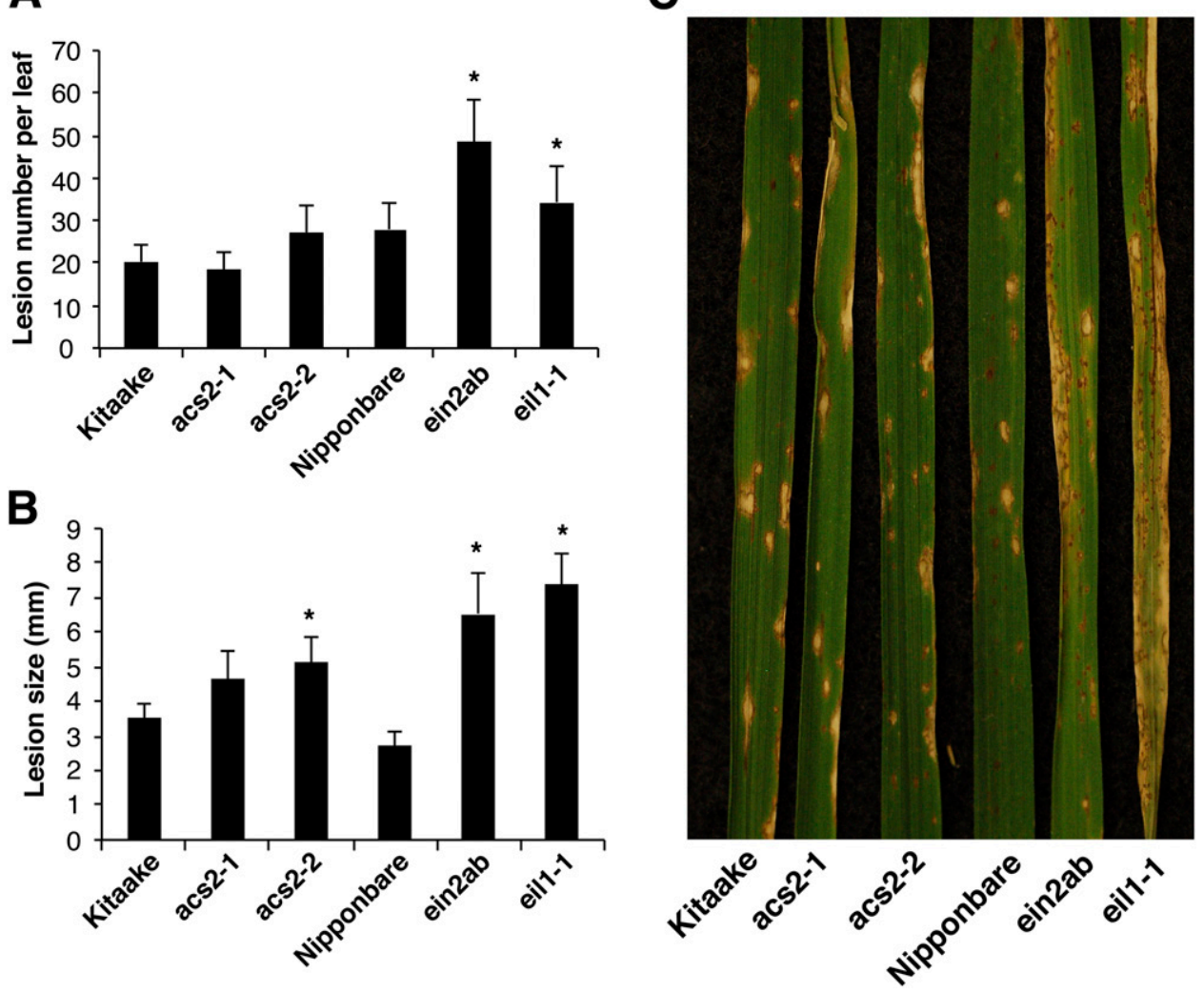

Fig. 7. Evaluation of the ethylene-deficient or -insensitive transgenic lines for resistance to spray-inoculated Magnaporthe oryzae 70-15. A, Lesion number per leaf after inoculation with $M$. oryzae $70-15$. B, Lesion size after inoculation with $M$. oryzae $70-15$. C, Representative disease symptoms at 7 days postinoculation with $M$. oryzae 70-15. Data represent the averages of at least three independent biological replicates. Asterisks represent significant differences from the control, determined by one-way analysis of variance. 
and -insensitive rice lines showed a significantly decreased and delayed induction of these genes under both basal and inoculated conditions, suggesting an attenuation of basal defense responses.

Under basal conditions, there is a $\mathrm{pH}$ gradient between the cytosol and the apoplast that is maintained by assorted ion pumps, namely $\mathrm{H}^{+}$-ATPases, which actively pump $\mathrm{H}^{+}$into the apoplast space to drive nutrient transport (Marre 1979). A rapid response to a potential nonself entity is the alkalinization of the apoplastic space and acidification of cytosolic space due to depolarization of the plasma membrane and results in rapid ion exchanges between the apoplast, cytoplast, and vacuole. This rapid response is used as a marker for the host plant response to elicitation (Elmore and Coaker 2011). Acidification of the cytosol is an important step in defense signaling; as cytosolic acidification of tobacco cells results in an increase in expression of defense-related genes $P A L$ and $H M G R$. This response was also seen in Mimosa pudica cells after treatment with varying concentrations of chitosan, a derivative of fungal cell-wall component chitin. After application of chitosan, there was a transient rise in the $\mathrm{pH}$ of culture fluid, brought on by inhibition of the plasma membrane $\mathrm{H}^{+}$-ATPase (Amborabé et al. 2008). Plasma membrane $\mathrm{H}^{+}$-ATPase activity has been implicated in plant cell response to salt stress, as they drive the efflux of excess $\mathrm{Na}^{+}$by the $\mathrm{Na}^{+} / \mathrm{H}^{+}$antiporter (Shi et al. 2000). Ethylene has also been implicated in response to salt stress in Arabidopsis. Wang et al. (2009) noted that ethylene-insensitive (etrl-1) Arabidopsis cells showed significantly decreased $\mathrm{H}^{+}$-ATPase activity and higher sensitivity to salt stress. Along these same lines, application of ACC increased the plasma membrane $\mathrm{H}^{+}$-ATPase activity in wild-type cells (Wang et al. 2009). In this study, we found two interesting points from both water- and elicitor-treated cells. First, the water-treated ethylene-insensitive cell cultures as well as the corresponding elicitor-treated cell cultures showed an overall more-alkaline $\mathrm{pH}$ than the nontransformed control and ethylene-deficient cell cultures. Second, there was a delay in alkalinization in the elicited ethylene-insensitive cell cultures as well as a lower peak difference in $\mathrm{pH}$ between the elicitor-treated sample and the water-treated sample. This suggests that inhibition of $\mathrm{H}^{+}$-ATPase does not occur to the same extent as it occurs in the nontransformed and ethylene-deficient lines. $\mathrm{pH}$ measurements of elicited ethylene-insensitive eill $1-1$ cells showed similar results, which shows that media alkalinization is dependent on ethylene signaling but not necessarily ethylene production. Previous studies have shown that inhibition of the $\mathrm{H}^{+}$-ATPase results in rapid ion fluctuations, including efflux of $\mathrm{K}^{+}$and influx of $\mathrm{Ca}^{2+}$, which is a common and ubiquitous second messenger (Amborabé et al. 2008; Elmore and Coaker 2011; Keinath et al. 2010; Nühse et al. 2007; Ward et al. 2009). Taken together, our results imply that there is an overall inhibition of H+-ATPase activity in the ethyleneinsensitive cell cultures, corresponding to results presented by Schaller and Oecking (1999), in which inhibition of $\mathrm{H}^{+}$-ATPases led to alkalinization of cell culture media. We believe that this inhibition of $\mathrm{H}^{+}$-ATPases in the ethylene-insensitive lines results in an overall de-sensitization to elicitors, which would, in turn, result in a reduction in the magnitude of apoplastic alkalinization. The $\mathrm{pH}$ data in this study also shows a third piece of information. At later time points, the $\mathrm{pH}$ of the bathing media drops beyond the basal level into the negative or acidic range, with the $\mathrm{pH}$ of the nontransformed 'Kitaake' cells dropping the lowest and the ethylenedeficient and -insensitive mutant lines dropping to the baseline only or just below it. This mimics acidification of the apoplastic space. Apoplastic acidification has been observed in cases of specific resistance, usually attributed to activation or reactivation of the $\mathrm{H}^{+}$-ATPase (Vera-Estrella et al. 1994). In the case of the incompatible barley-powdery mildew (Erysiphe graminis) interaction, apoplastic acidification is correlated with HR-like cell death (Zhou et al. 2000). This is a likely explanation, as the cells of the elicited nontransformed 'Kitaake' turned to a dark shade of brown and the bathing media turned offcolor. These changes were noticeable $24 \mathrm{~h}$ posttreatment in the elicited 'Kitaake' cells but not in the mock-inoculated 'Kitaake' cells. Darkening occurred slightly in the elicited ethylene-deficient acs 2-2 cell cultures as well as in the ethylene-insensitive eill-1 cell cultures, suggesting that acs 2-2 and eill-1 lines have lower rates of cell death, compared with nontransformed 'Kitaake' cells, in response to elicitation.

The role of ethylene in early HR-like cell death has been well documented (Asai et al. 2002; Gallie and Young 2004; Liu et al. 2008; Lund et al. 1998; Moeder et al. 2002; Overmyer et al. 2003). In this study, we used two different methods to measure cell death. The first method involved either staining elicitortreated cell cultures or leaves spot-inoculated with various $M$. oryzae isolates. The stain we used was Evans blue, an azo dye that binds to permeable membranes. In both assays, cell death was quantified by measuring the intensity of the stain bound to dead cells, relative to ethanol-treated samples (Delledonne et al. 2001; Kim et al. 2008). The ethylene-insensitive ein $2 a b-1$ and eill-1 lines showed a drastic reduction of cell death in both cell cultures treated with the elicitor and intact leaves inoculated with all three isolates of $M$. oryzae, whereas the ethylenedeficient cell cultures showed an intermediate reaction that varied depending on the $M$. oryzae isolate used. The fact that OsACS2-RI lines did not show clear reduction in cell death after spot-inoculation by the two virulent isolates of M. oryzae, $70-15$ and IE1K, but only showed a slight reduction by the noninfectious entities like the cell-wall elicitor or the avirulent isolate of $M$. oryzae is reminiscent of a race-specific interaction, as appearance of HR-like cell death is dependent on the avirulence of the pathogen. Previous work has suggested the involvement of ethylene biosynthesis, namely $O s A C S 2$, in racespecific resistance (Iwai et al. 2006; Seo et al. 2011). However, these results seem contradictory, as ethylene-mediated HR-like cell death should occur more frequently when exposed to a noninfectious entity such as a fungal elicitor or an avirulent pathogen. To verify that our conclusions from the staining results were accurate, we used another method of quantifying cell death. This involved measuring the conductivity of the bathing media of elicited and mock-elicited cells to quantify ion leakage. This data are generally consistent with the results from the Evans blue staining experiments, as even the intermediate cell-death phenotype seen in the stained acs $2-2$ cells showed a reduction in cell death when exposed to fungal elicitors. However, the acs $2-2$ cells showed a low rate of ion leakage, comparable to the ethylene-insensitive eill-1 and ein $2 a b-1$ lines, which showed a much lower degree of cell death in the staining experiments. Further experimentation will be required to investigate the composition of the bath media of each line in regards to which ions and at which concentrations are being released into the bathing media.

Our results show that ethylene-insensitive rice exhibits higher levels of susceptibility to rice blast disease than ethylenedeficient and nontransformed rice. In comparison with ethyleneinsensitive eill-1, eill-4 and ein $2 a b-1$ lines, the ethylene-deficient OsACS2-RI (acs2-1, acs 2-2) lines showed an intermediate susceptibility, with one of the two OsACS2-RI lines showing significantly larger lesions compared with nontransformed lines. This result was consistent with not only the resulting necrotic lesions in the punch-inoculation assay but also with the quantification of viable GFP-tagged $M$. oryzae. To fully assess disease severity, it is important to assess damage to the 
host as well as the ability of the pathogen to colonize the host. As the ethylene-insensitive lines had the highest number of lesions, the largest lesions, and the largest quantity of viable $M$. oryzae, we conclude that ethylene signaling is likely more critical than ethylene biosynthesis for mediating rice basal resistance.

In summary, we have shown that ethylene is produced as a part of basal defense in response to fungal elicitation. Ethyleneinsensitive lines show a reduction in transcription of a PAMP response receptor, $C E B i P$, reduced basal defense gene expression, delayed membrane depolarization, lower rates of early HR-like cell death, reduced callose deposition, and finally, reduced resistance to $M$. oryzae. Ethylene-deficient lines show many of these same effects, albeit to a more intermediate extent. Together, these results demonstrate that rice basal resistance to $M$. oryzae requires the signaling pathway as well as production of ethylene.

\section{MATERIALS AND METHODS}

\section{Plant and fungal materials.}

To grow rice plants for inoculation, seeds were germinated for 3 days in deionized water at $30^{\circ} \mathrm{C}$ and, then, planted in MetroMix 360 soil (SunGro, Bellevue, WA, U.S.A.) in greenhouse conditions (12 h of light, 28 and $24^{\circ} \mathrm{C}$ day and night, respectively). All $M$. oryzae isolates were grown from frozen stock on oatmeal agar at $22^{\circ} \mathrm{C}$ for 7 to 10 days under fluorescent light. Conidial suspensions were adjusted to a concentration of $2.5 \times 10^{5}$ conidia/ml, with $0.1 \%$ Tween-20. Spray inoculations were done by hand-spraying 14-day-old plants evenly with a conidial suspension until run-off occurred, and then, incubating all inoculated plants for $24 \mathrm{~h}$ in a sealed moist plastic container. Disease severity was measured at $7 \mathrm{dpi}$ by counting the number of lesions and measuring the three largest lesions per leaf. $M$. oryzae spot inoculations were done, following the protocol of Jia et al. (2003), by excising 6-cm sections of the third leaf from 21-day-old (four-leaf stage) plants and placing them on wetted blot paper within clear plastic boxes. Three 5- $\mu$ d drops of $M$. oryzae conidial suspension (prepared as described above) were placed on the abaxial side of each leaf, and the leaves were stained 3 days later with Evans blue. For the punch-inoculation assay, three or four $0.5-\mathrm{mm}$ puncture marks (about $2.5 \mathrm{~cm}$ apart on each leaf) were made on the third leaves of 21-day-old rice plants, and then, $5-\mu l$ drops of conidial suspension (prepared as described above) were placed on top of each puncture mark and plants were sealed inside a moist chamber for $24 \mathrm{~h}$. Disease was scored by measuring the length of each resulting necrotic lesion 1 week later. Alternatively, when a GFP-tagged strain of $M$. oryzae was used, the viable fungi were quantified by visualizing each lesion under a fluorescent stereomicroscope (Leica) on low power with a GFP filter, and the area and relative fluorescence was calculated using ImageJ (Schneider et al. 2012).

\section{Establishment and maintenance of rice cell cultures.}

De-husked seeds were soaked briefly in $70 \%$ ethanol and were then sterilized in a $50 \%$ Clorox $(2.6 \%$ sodium bicarbonate) solution with $0.1 \%$ Tween-20 for $30 \mathrm{~min}$. Sterilized seeds were rinsed at least three times in sterile deionized water and were plated onto callus induction media containing Chu N6 basal salt and vitamin, $2 \mathrm{~g}$ of Gelrite per liter, $30 \mathrm{~g}$ of sucrose per liter, and $2 \mathrm{mgl} 2,4-\mathrm{D}$, adjusted to $\mathrm{pH}=5.7$. The plates were incubated at $28^{\circ} \mathrm{C}$ with $12 \mathrm{~h}$ of light for 3 weeks. Resulting calli were placed in $50 \mathrm{ml}$ of liquid media (identical to callus induction media, without the Gelrite) in $28^{\circ} \mathrm{C}$, with $12 \mathrm{~h}$ of light, shaking at $150 \mathrm{rpm}$ and were subcultured every 5 to 8 days.

\section{Extraction and quantification} of $M$. oryzae cell-wall elicitors.

M. oryzae 70-15 was grown on oatmeal agar for 7 days, and ten $1-\mathrm{cm}$ plugs were inoculated into $250 \mathrm{ml}$ of yeastsucrose medium ( $1 \%$ sucrose, $0.2 \%$ yeast extract). Liquid cultures were incubated at $28^{\circ} \mathrm{C}$ for 3 days on a shaker (150 rpm). Excess media was filtered out and mycelia was rinsed twice with deionized water and was homogenized with a mortar and pestle with liquid nitrogen. The resulting powdered mycelia was resuspended in $25 \mathrm{ml}$ of TE buffer (10 mM Tris; $1 \mathrm{mM}$ EDTA, $\mathrm{pH}=8.0$ ), was sonicated for $1 \mathrm{~min}$ ( $50 \%$ cycle), and was centrifuged for $5 \mathrm{~min}$ at $3,500 \times \mathrm{g}$. The liquid phase was discarded, and the previous step was repeated. The resulting pellet was dried in an oven for $8 \mathrm{~h}$ at $110^{\circ} \mathrm{C}$.

The glucose content of the isolated fungal cell wall was quantified using the phenol-sulfuric acid method (DuBois et al. 1956). Cell-wall material $(10 \mathrm{mg})$ was suspended in $1 \mathrm{ml}$ of deionized water and 2 volumes $(10$ and $30 \mu \mathrm{l})$ were added to $100 \mu \mathrm{l}$ of $5 \%$ phenol and $300 \mu \mathrm{l}$ of $96 \% \mathrm{H}_{2} \mathrm{SO}_{4}$. The reactions were incubated at room temperature for $10 \mathrm{~min}$, and the absorbance at $490 \mathrm{~nm}$ was measured using a spectrophotometer. The glucose content was calculated using a standard curve of known concentrations.

\section{Gene constructs and rice transformation.}

A 0.6-kb cDNA sequence unique to $O s A C S 2$ was amplified from the OsACS2 full-length cDNA (AK064250), using a pair of specific primers (forward primer: $5^{\prime}$-ACC TCG AGA TGG CGT ACC AGG GCA TCG AC-3', reverse primer: 5'-ACC GTC GAC ACT GCT GGC TTA ATC AGC TG-3'). The fragments were inserted into the pANDA RNAi vector, which contains a constitutive ubiquitin promoter, in both forward and reverse directions. The resulting construct was transformed into Agrobacterium tumefaciens EHA105 via electroporation. The Agrobacterium-mediated rice transformation was performed using calli derived from seeds of 'Kitaake' as described previously (Mei et al. 2007). The T0 lines were self-pollinated, and the resulting $\mathrm{T} 1$ seeds were germinated in a hygromycin $(25 \mu \mathrm{g} / \mathrm{ml})$ solution. Roughly $75 \%$ of the seeds germinated, were grown in Metro Mix 360 soil (Sun Gro), and were maintained as described previously.

\section{Ethylene measurement.}

Rice leaves were excised from uninoculated or inoculated lines, were weighed, and were enclosed in a 4-ml glass vial for $2 \mathrm{~h}$ at room temperature. Two 1-ml samples were injected per vial, at specific time points, into a gas chromatograph (HewlettPackard 6890, Hewlett Packard, Palo Alto, CA, U.S.A.). Ethylene production was quantified in parts per million, based on an ethylene standard, and were converted to nanoliters per gram per hour.

\section{RNA extraction and cDNA synthesis.}

Rice leaf tissues (six leaves per sample) or $0.5 \mathrm{~g}$ of cultured cells were snap-frozen using liquid nitrogen, and total RNA was extracted from $100 \mathrm{mg}$ of powdered material, using TRIzol reagent (Invitrogen, Carlsbad, CA, U.A.A.). RNA pellets were washed at least twice with $70 \%$ ethanol pretreated with diethylpyrocarbonate (DEPC) and were resuspended in DEPCtreated sterile deionized water. Traces of genomic DNA were removed by treating RNA samples with DNase I (New England Biolabs, Ipswich, MA, U.S.A.) according to the manufacturer's instructions. cDNA was synthesized from each sample, using the High capacity reverse transcription kit (Applied Biosystems, Foster City, CA, U.S.A.) according to the manufacturer's instructions. 


\section{qPR-PCR.}

All qRT-PCR was done using a Step One Plus real-time PCR system (Applied Biosystems). Reactions were performed by the DyNAmo SYBR green PCR kit (New England Biolabs), according to the manufacturer's instructions. The cycling protocol began with a DNA denaturing step for $15 \mathrm{~min}$ at $94^{\circ} \mathrm{C}$, followed by 40 cycles of $30 \mathrm{~s}$ at $94^{\circ} \mathrm{C}, 45 \mathrm{~s}$ at $60^{\circ} \mathrm{C}$, and $45 \mathrm{~s}$ at $72^{\circ} \mathrm{C}$. Gene expression was quantified using the $\Delta \Delta \mathrm{Ct}$ (cycle threshold) method and was normalized by the rice ubiquitin 1 gene. A list of primers used is shown in Supplementary Table S1.

\section{pH and conductivity measurements.}

At 5 days postsubculture, cells $(1 \mathrm{~g})$ were incubated in $25 \mathrm{ml}$ of liquid media and were treated with either the fungal cell-wall elicitor $(30 \mathrm{ng} / \mathrm{ml})$ or an equivalent volume of water. At each time point, $\mathrm{pH}$ and conductivity (as $\mu \mathrm{S} / \mathrm{cm}$ ) of the liquid media was measured by a $\mathrm{pH}$ meter or a conductivity meter, respectively. The difference between waterand fungal elicitor-treated samples was plotted over the time course.

\section{Evans blue staining.}

At 5 days postsubculture, cultured cells $(0.1 \mathrm{~g})$ were placed in $1 \mathrm{ml}$ of liquid medium and were rotated at room temperature for $1 \mathrm{~h}$ to acclimate, with three reactions per transgenic line. Buffer was replaced after $1 \mathrm{~h}$ in two of the three reactions; cells of the third reaction per line were treated with ethanol. Cells in liquid media were either treated with $15 \mathrm{ng} / \mathrm{ml}$ of the fungal cell-wall elicitor or an equivalent volume of sterile deionized water for $24 \mathrm{~h}$. Cells were treated with $0.05 \%$ Evans blue (Sigma, St. Louis) in $1 \times$ phosphate buffered saline (PBS) for $30 \mathrm{~min}$ and were then rinsed three times with deionized water to remove unbound dye. Dead cells were destained by rotating overnight at room temperature in $50 \%$ methanol $+1 \%$ sodium dodecyl sulfate (SDS) solution. The absorbance of the destaining solution was measured at $600 \mathrm{~nm}$, using the water-treated cells as a blank, and the percentage of dead cells due to elicitation was calculated based on the absorbance of ethanol-treated cells.

To stain spot-inoculated rice leaves, three leaf disks centered around each inoculation point (approximately 2 to 3 dpi) were cut from each leaf and were placed in a microcentrifuge tube containing $0.5 \mathrm{ml}$ of $0.25 \%$ Evans blue + $0.1 \%$ Tween-20 in $1 \times$ PBS. The samples were rotated at room temperature for 25 to $30 \mathrm{~min}$. The excess stain was rinsed away two or three times with distilled $\mathrm{H}_{2} \mathrm{O}$, and leaf disks were dried under a sterile flow hood. The leaf disks were snap-frozen in liquid nitrogen and $0.5 \mathrm{ml}$ of $50 \%$ methanol + $1 \%$ SDS destaining solution was added. The samples were incubated for $8 \mathrm{~h}$ at $37^{\circ} \mathrm{C}$ in a shaker $(150 \mathrm{rpm})$. The tubes were centrifuged at $13,000 \times g$ for 5 min to pellet leaf debris and the absorbance was measured at $600 \mathrm{~nm}$ (subtract $662 \mathrm{~nm}$, the peak absorption of chlorophyll). The values were adjusted relative to the nontransformed controls (set at 1) for analysis.

\section{Quantification of callose deposition.}

Spot-inoculated rice leaves were cleared for 2 days in $95 \%$ ethanol and were then rinsed in $70 \mathrm{mM}$ phosphate buffer $(\mathrm{pH}=$ 9) for $30 \mathrm{~min}$. Leaves were incubated in $0.1 \%$ aniline blue and $70 \mathrm{mM}$ phosphate buffer for $2 \mathrm{~h}$, then, were rinsed briefly in $0.01 \%$ aniline blue, $70 \mathrm{mM}$ phosphate buffer. Samples were visualized using a fluorescence stereomicroscope with a UV filter, and callose deposition was quantified by counting the number of foci per square millimeter frame in the center of each inoculated spot.

\section{ACKNOWLEDGMENTS}

We thank K. Xie for technical advice and G. Sandoya for assistance with statistical analyses. We also thank W. Liu, J. Chen, and Y. Chen for helpful comments. This work is supported by Agriculture and Food Research Initiative Competitive grants 2008-35301-19028 and 2013-68004-20378 from the United States Department of Agriculture National Institute of Food and Agriculture.

\section{LITERATURE CITED}

Agrawal, G. K., Rakwal, R., and Jwa, N.-S. 2001. Differential induction of three pathogenesis-related genes, $P R 10, P R 1 b$, and $P R 5$ by the ethylene generator ethephon under light and dark rice (Oryza sativa L.) seedlings. J. Plant Physiol. 158:133-137.

Alonso, J. M., Hirayama, T., Roman, G., Nourizadeh, S., and Ecker, J. R. 1999. EIN2, a bifunctional transducer of ethylene and stress responses in Arabidopsis. Science 284:2148-2152.

Amborabé, B.-E., Bonmort, J., Fleurat-Lessard, P., and Roblin, G. 2008. Early events induced by chitosan on plant cells. J. Exp. Bot. 59: 2317-2324.

Anderson, J. P., Badruzsaufari, E., Schenk, P. M., Manners, J. M., Desmond, O. J., Ehlert, C., Maclean, D. J., Ebert, P. R., and Kazan, K. 2004 Antagonistic interaction between abscisic acid and jasmonate-ethylene signaling pathways modulates defense gene expression and disease resistance in Arabidopsis. Plant Cell 16:3460-3479.

Asai, T., Tena, G., Plotnikova, J., Willmann, M. R., Chiu, W. L., GomezGomez, L., Boller, T., Ausubel, F. M., and Sheen, J. 2002. MAP kinase signaling cascade in Arabidopsis innate immunity. Nature 415:977-983.

Bailey, T. A., Zhou, X., Chen, J., and Yang, Y. 2009. Role of ethylene, abscisic acid and MAP kinase pathways in rice blast resistance. Pages 185-190 in: Advances in Genetics, Genomics and Control of Rice Blast Disease. G.-L.Wang, and B. Valent, eds. Springer Netherlands, Amsterdam.

Bent, A. F., Innes, R. W., Ecker, J. R., and Staskawicz, B. J. 1992. Disease development in ethylene-insensitive Arabidopsis thaliana infected with virulent and avirulent Pseudomonas and Xanthomonas pathogens. Mol. Plant-Microbe Interact. 5:372-378.

Boutrot, F., Segonzac, C., Chang, K. N., Qiao, H., Ecker, J. R., Zipfel, C., and Rathjen, J. P. 2010. Direct transcriptional control of the Arabidopsis immune receptor FLS2 by the ethylene-dependent transcription factors EIN3 and EIL1. Proc. Natl. Acad. Sci. U.S.A. 107:1450214507.

Chae, H. S., and Kieber, J. J. 2005. Eto Brute? Role of ACS turnover in regulating ethylene biosynthesis. Trends Plant Sci. 10:291-296.

Chen, H., Xue, L., Chintamanani, S., Germain, H., Lin, H., Cui, H., Cai, R., Zuo, J., Tang, X., Li, X., Guo, H., and Zhou, J.-M. 2009. ETHYLENE INSENSITIVE3 and ETHYLENE INSENSITIVE3-LIKE1 repress SALICYLIC ACID INDUCTION DEFICIENT2 expression to negatively regulate plant innate immunity in Arabidopsis. Plant Cell 21: 2527-2540.

Chen, J. 2009. Molecular, biochemical, and functional characterization of rice MAP kinase substrates. Ph.D. dissertation. Pennsylvania State University, University Park, PA, U.S.A.

Cohn, J. R., and Martin, G. B. 2005. Pseudomonas syringae pv. tomato type III effectors AvrPto and AvrPtoB promote ethylene-dependent cell death in tomato. Plant J. 44:139-154.

De Vleesschauwer, D., Yang, Y., Cruz, C. V., and Höfte, M. 2010. Abscisic acid-induced resistance against the brown spot pathogen Cochliobolus miyabeanus in rice involves MAP kinase-mediated repression of ethylene signaling. Plant Physiol. 152:2036-2052.

Delledonne, M., Zeier, J., Marocco, A., and Lamb, C. 2001. Signal interactions between nitric oxide and reactive oxygen intermediates in the plant hypersensitive disease resistance response. Proc. Natl. Acad. Sci. U.S.A. 98:13454-13459.

DuBois, M., Gilles, K., Hamilton, J., Rebers, P., and Smith, F. 1956. Colorimetric method for determination of sugars and related substances. Anal. Chem. 28:350-356.

Elmore, J. M., and Coaker, G. 2011. The role of the plasma membrane $\mathrm{H}^{+}$-ATPase in Plant-Microbe Interact.ions. Mol. Plant 4:416-427.

Gallie, D. R., and Young, T. E. 2004. The ethylene biosynthetic and perception machinery is differentially expressed during endosperm and embryo development in maize. Mol. Genet. Genomics 271: 267-281.

Geraats, B. P. J., Bakker, P. A. H. M., Lawrence, C. B., Achuo, E. A., Höfte, M., and van Loon, L. C. 2003. Ethylene-insensitive tobacco shows differentially altered susceptibility to different pathogens. Phytopathology 93:813-821. 
Gust, A. A., Brunner, F., and Nürnberger, T. 2010. Biotechnological concepts for improving plant innate immunity. Curr. Opin. Biotechnol. 21:204-210.

Hammond-Kosack, K. E., and Jones, J. D. G. 1996. Resistance genedependent plant defense responses. Plant Cell 8:1773-1791.

Harp, T. L., and Correll, J. C. 1998. Recovery and characterization of spontaneous, selenate-resistant mutants of Magnaporthe grisea, the rice blast pathogen. Mycologia 90:954-963.

Helliwell, E. E., Wang, Q., and Yang, Y. 2013. Transgenic rice with inducible ethylene production exhibits broad-spectrum disease resistance to the fungal pathogens Magnaporthe oryzae and Rhizoctonia solani. Plant Biotechnol. J. 11:33-42.

Higo, K., Ugawa, Y., Iwamoto, M., and Korenaga, T. 1999. Plant cis-acting regulatory DNA elements (PLACE) database: 1999. Nucleic Acids Res. 27:297-300

Hoffman, T., Schmidt, J. S., Zheng, X., and Bent, A. F. 1999. Isolation of ethylene-insensitive soybean mutants that are altered in pathogen susceptibility and gene-for-gene disease resistance. Plant Physiol. 119: 935-950.

Iwai, T., Miyasaka, A., Seo, S., and Ohashi, Y. 2006. Contribution of ethylene biosynthesis for resistance to blast fungus infection in young rice plants. Plant Physiol. 142:1202-1215.

Jia, Y., and Martin, G. B. 1999. Rapid transcript accumulation of pathogenesis-related genes during an incompatible interaction in bacterial speck disease-resistant tomato plants. Plant Mol. Biol. 40: 455-465.

Jia, Y., Valent, B., and Lee, F. N. 2003. Determination of host responses to Magnaporthe grisea on detached rice leaves using a spot inoculation method. Plant Dis. 87:129-133.

Ju, C., Yoon, G. M., Shemansky, J. M., Lin, D. Y., Ying, Z. I., Chang, J., Garrett, W. M., Kessenbrock, M., Groth, G., Tucker, M. L., Cooper, B., Kieber, J. J., and Chang, C. 2012. CTR1 phosphorylates the central regulator EIN2 to control ethylene hormone signaling from the ER membrane to the nucleus in Arabidopsis. Proc. Natl. Acad. Sci. U.S.A. 109:19486-19491.

Kaku, H., Nishizawa, Y., Ishii-Minami, N., Akimoto-Tomiyama, C., Dohmae, N., Takio, K., Minami, E., and Shibuya, N. 2006. Plant cells recognize chitin fragments for defense signaling through a plasma membrane receptor. Proc. Natl. Acad. Sci. U.S.A. 103:11086-11091.

Keinath, N. F., Kierszniowska, S., Lorek, J., Bourdais, G., Kessler, S. A., Shimosato-Asano, H., Grossniklaus, U., Schulze, W. X., Robatzek, S., and Panstruga, R. 2010. PAMP (pathogen-associated molecular pattern)induced changes in plasma membrane compartmentalization reveal novel components of plant immunity. J. Biol. Chem. 285:39140-39149.

Kim, K. S., Min, J. Y., and Dickman, M. B. 2008. Oxalic acid is an elicitor of plant programmed cell death during Sclerotinia sclerotiorum disease development. Mol. Plant-Microbe Interact. 21:605-612.

Kishimoto, K., Kouzai, Y., Kaku, H., Shibuya, N., Minami, E., and Nishizawa, Y. 2010. Perception of the chitin oligosaccharides contributes to disease resistance to blast fungus Magnaporthe oryzae in rice. Plant J. 64:343-354.

Lim, P. O., Kim, H. J., and Nam, H. G. 2007. Leaf senescence. Annu. Rev. Plant Biol. 58:115-136.

Liu, H., Wang, Y., Xu, J., Su, T., Liu, G., and Ren, D. 2008. Ethylene signaling is required for the acceleration of cell death induced by the activation of AtMEK5 in Arabidopsis. Cell Res. 18:422-432.

Lund, S. T., Stall, R. E., and Klee, H. J. 1998. Ethylene regulates the susceptible response to pathogen infection in tomato. Plant Cell 10: 371-382.

Mao, C., Wang, S., Jia, Q., and Wu, P. 2006. OsEIL1, a rice homolog of the Arabidopsis EIN3 regulates the ethylene response as a positive component. Plant Mol. Biol. 61:141-152.

Marre, E. 1979. Fusicoccin: A tool in plant physiology. Annu. Rev. Plant Physiol. 30:273-288.

Mei, C., Zhou, X., and Yang, Y. 2007. Use of RNA interference to dissect defense-signaling pathways in rice. Methods Mol. Biol. 354:161-171.

Mersmann, S., Bourdais, G., Rietz, S., and Robatzek, S. 2010. Ethylene signaling regulates accumulation of the FLS2 receptor and is required for the oxidative burst contributing to plant immunity. Plant Physiol. 154:391-400.

Moeder, W., Barry, C. S., Tauriainen, A. A., Betz, C., Tuomainen, J., Utriainen, M., Grierson, D., Sandermann, H., Langebartels, C., and Kangasjärvi, J. 2002. Ethylene synthesis regulated by biphasic induction of 1-aminocyclopropane-1-carboxylic acid synthase and 1 -aminocyclopropane-1-carboxylic acid oxidase genes is required for hydrogen peroxide accumulation and cell death in ozone-exposed tomato. Plant Physiol. 130:1918-1926.
Niks, R. E., and Marcel, T. C. 2009. Nonhost and basal resistance: How to explain specificity? New Phytol. 182:817-828.

Nühse, T. S., Bottrill, A. R., Jones, A. M. E., and Peck, S. C. 2007 Quantitative phosphoproteomic analysis of plasma membrane proteins reveals regulatory mechanisms of plant innate immune responses. Plant J. 51:931-940.

Okada, A., Okada, K., Miyamoto, K., Koga, J., Shibuya, N., Nojiri, H., and Yamane, H. 2009. OsTGAP1, a bZIP transcription factor, coordinately regulates the inductive production of diterpenoid phytoalexins in rice. J. Biol. Chem. 284:26510-26518.

Otomo, K., Kanno, Y., Motegi, A., Kenmoku, H., Yamane, H., Mitsuhashi, W., Oikawa, H., Tashima, H., Itoh, H., Masuoka, M., and Toyomasu, Y. 2004. Diterpene cyclases responsible for the biosynthesis of phytoalexins, momilactones $\mathrm{A}, \mathrm{B}$, and oryzalexins $\mathrm{A}-\mathrm{F}$ in rice. Biosci. Biotechnol. Biochem. 68:2001-2006.

Overmyer, K., Brosché, M., and Kangasjärvi, J. 2003. Reactive oxygen species and hormonal control of cell death. Trends Plant Sci. 8: 335-342.

Qiao, H., Shen, Z., Huang, S. S., Schmitz, R. J., Urich, M. A., Briggs, S. P., and Ecker, J. R. 2012. Processing and subcellular trafficking of ER-tethered EIN2 control response to ethylene gas. Science 338: 390-393.

Sakamoto, T., Miura, K., Itoh, H., Tatsumi, T., Ueguchi-Tanaka, M., Ishiyama, K., Kobayashi, M., Agrawal, G. K., Takeda, S., Abe, K., Miyao, A., Hirochika, H., Kitano, H., Ashikari, M., and Matsuoka, M. 2004. An overview of gibberellin metabolism enzyme genes and their related mutants in rice. Plant Physiol. 134:1642-1653.

Schaller, A., and Oecking, C. 1999. Modulation of plasma membrane $\mathrm{H}^{+}$-ATPase activity differentially activates wound and pathogen defense responses in tomato plants. Plant Cell 11:263-272.

Schneider, C. A., Rasband, W. S., and Eliceiri, K. W. 2012. NIH Image to ImageJ: 25 years of image analysis. Nat. Methods 9:671-675.

Schwessinger, B., and Ronald, P. C. 2012. Plant innate immunity: Perception of conserved microbial signatures. Annu. Rev. Plant Biol. 63:451-482.

Seo, S., Mitsuhara, I., Feng, J., Iwai, T., Hasegawa, M., and Ohashi, Y. 2011. Cyanide, a coproduct of plant hormone ethylene biosynthesis, contributes to the resistance of rice to blast fungus. Plant Physiol. 155: $502-514$.

Shi, H., Ishitani, M., Kim, C., and Zhu, J. K. 2000. The Arabidopsis thaliana salt tolerance gene $S O S 1$ encodes a putative $\mathrm{Na}^{+} / \mathrm{H}^{+}$antiporter. Proc. Natl. Acad. Sci. U.S.A. 97:6896-6901.

Shimizu, T., Nakano, T., Takamizawa, D., Desaki, Y., Ishii-Minami, N., Nishizawa, Y., Minami, E., Okada, K., Yamane, H., Kaku, H., and Shibuya, N. 2010. Two LysM receptor molecules, CEBiP and OsCERK1, cooperatively regulate chitin elicitor signaling in rice. Plant J. 64:204-214.

Shimura, K., Okada, A., Okada, K., Jikumaru, Y., Ko, K.-W., Toyomasu, T., Sassa, T., Hasegawa, M., Kodama, O., Shibuya, N., Koga, J., Nojiri, H., and Yamane, H. 2007. Identification of a biosynthetic gene cluster in rice for momilactones. J. Biol. Chem. 282:34013-34018.

Singh, M. P., Lee, F. N., Counce, P. A., and Gibbons, J. H. 2004. Mediation of partial resistance to rice blast through anaerobic induction of ethylene. Phytopathology 94:819-825.

Solano, R., Stepanova, A., Chao, Q., and Ecker, J. R. 1998. Nuclear events in ethylene signaling: A transcriptional cascade mediated by ETHYLENE-INSENSITIVE3 and ETHYLENE-RESPONSE-FACTOR1. Genes Dev. 12:3703-3714.

Takai, R., Isogai, A., Takayama, S., and Che, F.-S. 2008. Analysis of flagellin perception mediated by flg22 receptor OsFLS2 in rice. Mol. Plant-Microbe Interact. 21:1635-1642.

Vera-Estrella, R., Higgins, V. J., and Blumwald, E. 1994. Plant defense response to fungal pathogens: II: G-protein mediate changes in host plasma membrane redox reactions. Plant Physiol. 106:97-102.

Wang, H., Liang, X., Wan, Q., Wang, X., and Bi, Y. 2009. Ethylene and nitric oxide are involved in maintaining ion homeostasis in Arabidopsis callus under salt stress. Planta 230:293-307.

Ward, J. M., Mäser, P., and Schroeder, J. I. 2009. Plant ion channels: Gene families, physiology, and functional genomics analyses. Annu. Rev. Physiol. 71:59-82.

Yang, S. F., and Hoffman, N. E. 1984. Ethylene biosynthesis and its regulation in higher plants. Annu. Rev. Plant Physiol. 35:155-189.

Zhou, F., Andersen, C. H., Burhenne, K., Fischer, P. H., Collinge, D. B., and Thordal-Christensen, H. 2000. Proton extrusion is an essential signalling component in the HR of epidermal single cells in the barley-powdery mildew interaction. Plant J. 23:245-254. 